\title{
Carbon nanomaterials in clean and contaminated soils: environmental implications and applications
}

\author{
M. J. Riding, F. L. Martin, K. C. Jones, and K. T. Semple \\ Lancaster University, Lancaster Environment Centre, Lancaster, LA1 4YQ, UK \\ Correspondence to: K. T. Semple (k.semple@lancaster.ac.uk)
}

Received: 2 June 2014 - Published in SOIL Discuss.: 20 June 2014

Revised: 12 November 2014 - Accepted: 17 November 2014 - Published: 5 January 2015

\begin{abstract}
The exceptional sorptive ability of carbon nanomaterials (CNMs) for hydrophobic organic contaminants (HOCs) is driven by their characteristically large reactive surface areas and highly hydrophobic nature. Given these properties, it is possible for CNMs to impact on the persistence, mobility and bioavailability of contaminants within soils, either favourably through sorption and sequestration, hence reducing their bioavailability, or unfavourably through increasing contaminant dispersal. This review considers the complex and dynamic nature of both soil and CNM physicochemical properties to determine their fate and behaviour, together with their interaction with contaminants and the soil microflora. It is argued that assessment of CNMs within soil should be conducted on a case-by-case basis and further work to assess the long-term stability and toxicity of sorbed contaminants, as well as the toxicity of CNMs themselves, is required before their sorptive abilities can be applied to remedy environmental issues.
\end{abstract}

\section{Introduction}

With the continued upscaling of carbon nanomaterial (CNM) production (Nowack and Bucheli, 2007) as well as the diverse array of consumer (Sharma and Ahuja, 2008), medical (Peretz and Regev, 2012) and industrial applications in which they are increasingly becoming incorporated, widespread environmental release of these physically and chemically unique macromolecules has become inevitable (Köhler et al., 2008). Once released, soils are likely to be a primary repository (Mueller and Nowack, 2008; Gottschalk et al., 2009), with the quantities anticipated to increase on an annual basis (Gottschalk et al., 2009). In spite of this, studies focused on CNMs within soils are scarce, and many areas of uncertainty remain. Understanding the interactions between CNMs, soils and components therein is therefore an urgent and essential aspect of any risk assessment process.

In their pristine form, CNMs are broadly characterised by their large reactive surface areas, highly hydrophobic characteristics and high degree of biogeochemical recalcitrance. They are known to be toxic to various soil microbiota (Riding et al., 2012a, b), and possess a high affinity for the sorption of a range of hydrophobic organic compounds
(HOCs), such as polycyclic aromatic hydrocarbons (PAHs), and polychlorinated biphenyls (PCBs) (Pan and Xing, 2010). As both PAHs and PCBs are important classes of hydrophobic, toxic organic compounds, which are both abundant and persistent in soils (Stokes et al., 2005), the potential for CNMs to modify the availability and mobility of HOCs, either favourably through sorption and sequestration, or unfavourably through increasing contaminant dispersal, is currently unknown. Presently, there is only limited and occasionally contradictory information regarding the implications of contaminants while sorbed to CNMs, as well as the fate and behaviour of CNMs in uncontaminated soils. Exploring these issues in light of the emerging nature of CNMs as xenobiotic soil components is therefore essential.

This review seeks to answer three key questions. (i) What factors influence the behaviour and fate of CNMs within the soil environment? (ii) To what extent can CNMs influence the sorption, desorption and mobility of contaminants in soils? (iii) What are the impacts of CNMs on soil microorganisms and the biodegradation of contaminants in soils? 


\section{Carbon nanomaterial diversity and detection}

Within the environment, some CNMs can occur naturally or have close naturally occurring relatives due to various environmental events (Heymann et al., 1994; Chijiwa et al., 1999; Velasco-Santos et al., 2003; Esquivel and Murr, 2004). However, concentrations occurring naturally are likely to be relatively small (0.1-0.2 parts per million) (Heymann et al., 1994; Chijiwa et al., 1999). Therefore, when referring to CNMs, this review explicitly focuses on those that are anthropogenic in origin.

The properties of CNMs vary dramatically between the different methods of production, functionalization status and cleaning/purification methods employed (Nowack and Bucheli, 2007). Hence, determining their environmental behaviour is all the more challenging, and generalisation of the characteristics of CNMs is not possible, with each type requiring careful characterisation (Nowack and Bucheli, 2007). Of the many different forms of CNMs available, this review focuses specifically on carbon nanotubes (CNTs) and $\mathrm{C}_{60}$ fullerene, which are two of the most widely utilised and investigated classes of CNMs (Mueller and Nowack, 2008; Gottschalk et al., 2009, 2010; Petersen and Henry, 2012).

To date, CNTs are arguably the most promising of all nanomaterials produced (Giles, 2006). In their pristine form, CNTs are extremely hydrophobic and consist of graphene sheets rolled into nanoscale diameter cylinders, the ends of which may contain spherical fullerene cappings (Mauter and Elimelech, 2008). One single-rolled graphite sheet is called a single-walled carbon nanotube (SWCNT), while several SWCNTs nested together in a concentric fashion comprise a multi-walled carbon nanotube (MWCNT) (Pan and Xing, 2008). They consist of $\mathrm{sp}^{2}$ carbon atom arrangements in a fused benzene ring configuration, which results in exceptional physicochemical properties and consequentially their incorporation into a vast array of composite materials (Liu et al., 1999; Snow et al., 2005; Mauter and Elimelech, 2008; Almecija et al., 2009). An excellent and more detailed discussion about the unique physicochemical properties of CNTs is provided by Mauter and Elimelech (2008).

Fullerenes are spherically arranged carbon atoms resembling a geodesic dome. The size of the fullerene dome can vary depending on the number and spherical configuration of carbon atoms. $\mathrm{C}_{60}$ fullerene (buckminsterfullerene or buckyball) has arguably the best defined physicochemical parameters, produced in the largest quantities, and has been the focus of most scientific engagement (Campbell and Rohmund, 2000; Petersen and Henry, 2012). $\mathrm{C}_{60}$ is comprised of a spherical configuration of 5- and 6-carbon rings, consisting of 60 carbon atoms in total. It commonly exists as nano$\mathrm{C}_{60}\left(n \mathrm{C}_{60}\right)$ particles (regarded as the most environmentally relevant form), which are crystalline structures containing 100-1000 C60 molecules (Colvin, 2003; Sayes et al., 2004). Presently, fullerenes have proposed applications in biology
(Lucafò et al., 2012) and electronic/optical devices as thin films combined with polymers (Richards et al., 2012).

Unlike most organic chemicals with well-defined structures, the diversity of particle sizes, lengths, diameters, charges, surface areas, coatings, molecular weight, impurities and aggregation states are not necessarily constant. These are often tailored to the intended end use of the particles and can be modified by the environmental compartments in which they reside, which limits their detection and characterisation in soils and other complex environmental matrices through chromatographic techniques (Petersen et al., 2011). A summary of methods used to detect CNMs within soils and sediments is presented in Table 1.

In addition, as the lifecycles of CNM-containing products are likely to vary greatly, the means by which these materials enter the soil environment are also likely to be highly variable (Pan and Xing, 2012). An excellent review of different CNM exposure scenarios, for both humans and the environment, is provided by Köhler et al. (2008). Further complicating their detection is the emerging nature of manufactured CNMs as soil xenobiotic components, and hence their presently low concentrations, together with their interaction with naturally occurring nanomaterials and other environmental components, which leads to particles with sizes and compositions that significantly differ from their native forms (Nowack and Bucheli, 2007; Darlington et al., 2009; Chen et al., 2011). As such, careful consideration of multiple environmental variables is required to determine their impact on CNM fate and behaviour.

\section{CNM behaviour and fate within the soil environment}

Once released into the soil, the fate and behaviour of CNMs is governed by their interactions with various components within the environment. Derjaguin-Landau-VerweyOverbeek (DLVO) interactions, such as electrostatic interactions and van der Waals (vdW) forces, and non-DLVO interactions, such as hydrogen bonding and steric hindrance, ultimately determine the mobility, aggregation and adhesion of CNMs within soils. These forces may operate in concert to various extents, with the predominating force controlled by factors such as the properties and quantity of soil organic matter (SOM), characteristics of inorganic matter, and the type and quantity of clays, together with the properties of CNMs themselves. Each of these factors are heavily influenced by variables that are not necessarily constant over time, such as $\mathrm{pH}$ and ionic strength.

\subsection{The impact of soil organic matter}

Soil organic matter plays a substantial role in both the fate and behaviour of CNMs through alterations in the dominance of the various DLVO and non-DLVO interactions. SOM (which consists primarily of decomposed plant and 


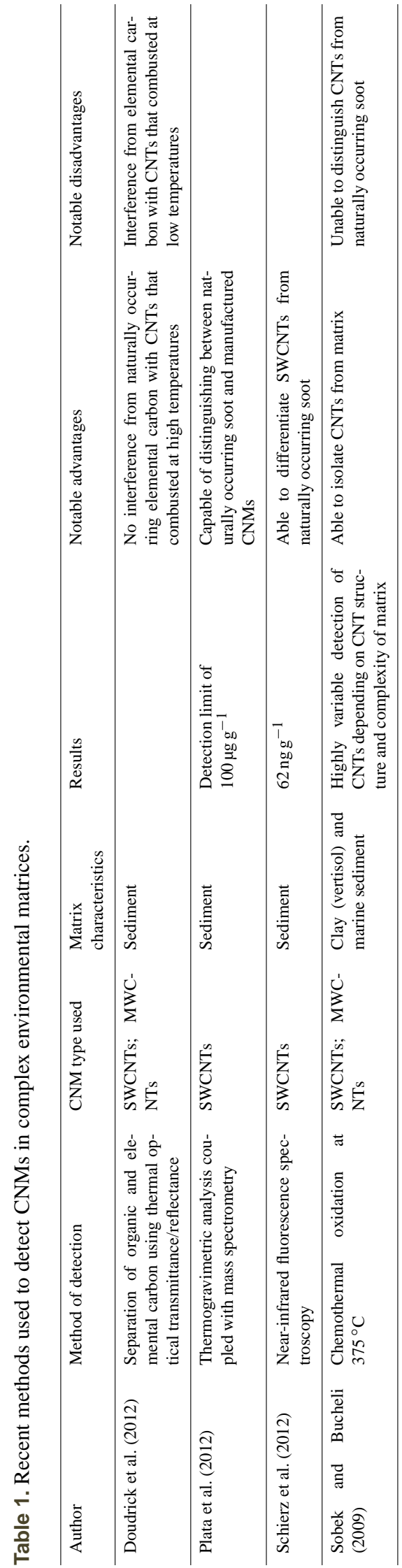

animal remains (Lee et al., 1981)) is an all-encompassing term describing organic matter (OM) dispersed ubiquitously throughout the soil environment, and is composed of a heterogeneous mixture of lipids, carbohydrates, carboxylic acids, humic substances, hydrophilic acids, proteins, carbohydrates, hydrocarbons and amino acids. However, the mechanism by which SOM maintains the CNM stability in suspension is still under investigation and debate (Dinesh et al., 2012). Specifically, the aim of this section is therefore to provide an overview of recent investigations in which the manner of solid SOM, dissolved organic matter (DOM), humic acid (HA) and tannic acid (TA) influence the behaviour of CNMs.

Adsorption of molecular DOM onto CNMs occurs through either aromatic ring sorption or binding of aliphatic chains via $\pi-\pi$ or $\mathrm{CH}-\pi$ interactions, leaving the hydrophilic moieties exposed (Lin and Xing, 2008). Consequentially, the surfaces of CNMs significantly change from a hydrophobic, aromatic-like structure to that of the organic, hydrophilic functional groups in DOM (Zhang et al., 2011a), with potentially large implications for other DLVO and non-DLVO interactions. In studying $n \mathrm{C}_{60}$, Kwon (2012) found the type of DOM-determined suspension stability, with those containing long, hydrophobic carbon backbones readily adsorbing via $v d W$ interactions onto $n \mathrm{C}_{60}$ surfaces, promoting their stability. However, Zhang et al. (2011a) found that peat (diagenetically young SOM) in dissolved form (DOM) also prevented MWCNT aggregation through both steric hindrance and electrostatic repulsion in sodium concentrations $>4 \mathrm{mM}$ or in solutions of $\mathrm{pH} \geq 4$ (Zhang et al., 2011a). Increasing ionic strength resulted in greater adsorption of DOM onto MWCNTs (Hyung et al., 2006; Hyung and Kim, 2008; Zhang et al., 2011a) due to reduced electrostatic repulsion between the DOM and the particle surface. As a result, cations impairing electrostatic interactions at high ionic strengths in the presence of DOM may slightly shift the relative importance of suspension mechanisms from electrostatic repulsion, in favour of steric hindrance (Zhang et al., 2011a); broadly similar results have been identified with $n \mathrm{C}_{60}(\mathrm{Qu}$ et al., 2012). Ionic strength therefore primarily affects the balance between electrostatic repulsion and steric hindrance mechanisms of particle suspension in the presence of DOM.

Typically, frequently occurring cations within the environment $\left(\mathrm{K}^{+}, \mathrm{Na}^{+}, \mathrm{Ca}^{+}\right.$and $\left.\mathrm{Mg}^{2+}\right)$ induce aggregation and deposition in systems devoid of SOM through reductions in electrostatic repulsion between particles, hence reducing CNM stability (Zhang et al., 2012b). The influence of cations on the behaviour of CNMs is well illustrated by the extent to which physical straining (filtering out) of $n \mathrm{C}_{60}$ occurs in saturated porous media. Zhang et al. (2012a) found that columns of pure quartz resulted in very limited nanoparticle deposition even at low flow velocities, whereas a heterogeneous sandy soil with low OM content and small, irregular and rough grains of sand, significantly inhibited $n \mathrm{C}_{60}$ transport. With the addition of $\mathrm{CaCl}_{2}$, greater deposition of $n \mathrm{C}_{60}$ 
was observed in both sand and soil; however, significantly more straining occurred in the soil due to the greater number of complexation sites for $\mathrm{Ca}^{2+}$ clay and OM fractions relative to sand (Zhang et al., 2012a). For both the sand and soil columns, $\mathrm{Ca}^{2+}$ had a much larger effect on the transport of $n \mathrm{C}_{60}$ than $\mathrm{Na}^{+}$at the same ionic strengths (Zhang et al., 2012a). This most likely occurred due to efficient neutralisation of surface charges on both $n \mathrm{C}_{60}$ and sand and soil particles by $\mathrm{Ca}^{2+}$ relative to $\mathrm{Na}^{+}$, which reduced the electrostatic repulsion (Kuznar and Elimelech, 2004; Zhang et al., 2012a).

When considering the fate and behaviour of CNMs in soils, solid peat may have a different impact to that of molecular DOM under environmentally relevant ionic conditions. This could be caused by the alteration of particle-phase distributions due to the direct sorption of CNMs, as well as the possibility of DOM or cations being release from the soil particles themselves (Zhang et al., 2011a). In the absence of sodium ions, Zhang et al. (2011a) found no adsorption of MWCNTs to solid peat, indicating a limited affinity of DOM-MWCNT composites towards the solid phase relative to the aqueous phase, possibly due to electrostatic repulsion and hydrophilicity of DOM-coated nanotubes. With the addition of $\mathrm{Na}^{+}$ions, the relative affinity between DOMMWCNTs and peat was increased due to reductions in the charge potential and subsequent increase in interactions occurring through hydrophobic interactions and/or vdW attraction (Zhang et al., 2011a). Zhang et al. (2011a) concluded that with increasing ionic strength (such as in environments containing seawater or hard freshwater), an increased precipitation of MWCNTs from the aqueous phase will occur, impeding their transport within the environment.

Consideration of the $\zeta$ potential (diffuse surface charge) of CNMs in relation to the soil matrix is important when considering the dynamics of smaller particles' dispersal, transport and deposition, for which charge forces are likely to be highly influential relative to larger particles or agglomerates (Darlington et al., 2009). Its measure, in part, provides information on the likely mobility, rates of interaction and aggregation status due to electrostatic forces generated by charged surfaces (Hu et al., 2005; Jafar and Hamzeh, 2013). Pristine CNTs typically express a limited surface charge (Mohanty et al., 2007); however, P. Wang et al. (2008) found that the $\zeta$ potential of CNTs with a HA coating was highly negative, which resulted in electrostatic repulsion between the particles and hence stability when partitioned into the aqueous phase. They concluded that mobility and environmental transport within typically negatively charged porous media, such as certain types of soils, was highly likely, with particles remaining stable over a wide range of ionic strengths (P. Wang et al., 2008). A reduction in $\mathrm{pH}$ to the point at which the CNTs had no charge was identified as an effective means of causing CNTs to precipitate, through the destabilization of the HA coatings (P. Wang et al., 2008).
The properties of the humic substances determine the extent to which DLVO and non-DLVO interactions influence particle behaviour. TA (Chibowski et al., 1998) and HA sorbed to CNTs enhance stabilisation in water through reducing vdW forces between particles and increasing steric repulsion (Terashima and Nagao, 2007; Ren et al., 2011). However, Qu et al. (2012) identified that high molecular weight (HMW) HAs were more effective in promoting suspension stability due to stronger steric repulsion than that of low molecular weight (LMW) HAs. Similarly, HAs containing large quantities surfactive domains, such as those which are strongly hydrophilic and lipophilic, promote the dispersal of CNTs in solutions, while those containing carbohydrates and predominantly hydrophilic domains resulted in limited dispersal (Chappell et al., 2009).

The composition of SOM in relation to ionic strength and $\mathrm{pH}$ dictates the behaviour of CNMs within soils. Presently, however, insufficient data regarding the relative impact of different SOM fractions and combinations on DLVO and non-DLVO forces in soils is lacking, reducing the ability to estimate how CNMs may behave based on analysis of soil OM content. Furthermore, in addition to the organic fraction of soils and coating of CNMs, the role of the inorganic fraction in determining particle behaviour must also be considered.

\subsection{The impact of soil inorganic matter}

In addition to the organic fraction, CNM stability in saturated soil-water suspensions is strongly influenced by the impact of the inorganic fraction, and is largely neglected within the present literature. Han et al. (2008) studied the impact of kaolinite and montmorillonite clay minerals with particle sizes of around $2 \mu \mathrm{m}$ on the stability of MWCNTs $\left(18 \mathrm{mg} \mathrm{L}^{-1}\right)$ suspended in three different surfactants (either cetyltrimethylammonium bromide (CTAB), dodecylbenzenesulfonic acid, sodium salt (SDBS), or octylphenol ethoxylate (TX100), each at $40 \mathrm{mg} \mathrm{L}^{-1}$ ). The study showed that MWCNTs stabilised by CTAB, became deposited in the presence of montmorillonite or kaolinite particles, which suggests MWCNTs may not move through soils or sediments containing these minerals, or that the addition of montmorillonite or kaolinite could be used to reduce their mobility and transport (Han et al., 2008). However, no investigation such as soil column leach testing was performed to specifically measure the movement of MWCNTs, and further direct measurements are required to verify the results in soils. Suspensions of CNTs in SDBS were not affected by the presence of either montmorillonite or kaolinite, and TX100 suspensions were not altered by kaolinite but were destabilised partially in montmorillonite (Han et al., 2008). The authors suggested that CNTs may be able to move through soils and sediments containing these clay minerals if suspended using SDBS or TX100. It was proposed that the destabilisation of surfactantdispersed MWCNTs occurs by two mechanisms: (i) removal 
of surfactants from solution by clay minerals and (ii) clay minerals bridging between MWCNTs and surfactants (Han et al., 2008).

Furthermore, the charge characteristics of soils can also influence the behaviour and fate of CNMs. Broadly, all soils can be divided into two groups: permanent-charge (P-C) and variable-charge (V-C) soils (Sollins et al., 1988). In P$\mathrm{C}$ soils, the substitution of ions with lower valence for ions with higher valence results in the alteration of crystal lattice structures within layer-silicate clays (illite, smectite, chlorite and kaolin) and a permanent charge deficit, which persists irrespective of variations in the composition of soil solutions and $\mathrm{pH}$ (Sollins et al., 1988). In V-C soils, protonation and deprotonation of surface hydroxyl groups results in the positive charge and hence anion exchange capacity (AEC), whereas deprotonation results in cation exchange capacity (CEC) (Sollins et al., 1988). The structure of V-C soils is also modified in response to increasing $\mathrm{pH}$, resulting in increased repulsion and more limited aggregation (Sollins et al., 1988). Both P-C and V-C surfaces are present in all soil types; however, only one charge system typically dominates, dictated largely by soil mineralogy (Sollins et al., 1988). While V-C soils occur more frequently in tropical regions due to the typical mineralogical composition which forms under humid, warm conditions, they do not occur ubiquitously, and many areas with predominantly P-C characteristics occur (Sanchez, 1976; Sollins et al., 1988). Hence, while V-C soils represent a small fraction of global soil types, interactions between nanoparticles and soils are likely to be much more dynamic relative to those with a P-C. Despite this, almost all investigations have predominantly focused on $\mathrm{P}-\mathrm{C}$ soils, restricting the applicability of CNM fate and behaviour investigations.

The behaviour of CNMs in V-C soils has been assessed by Zhang et al. (2012b), who investigated the stability of MWCNTs suspended in water containing either kaolinite, smectite or shale over a range of sodium concentrations. Without additional $\mathrm{Na}^{+}$, no significant difference in the stability of MWCNTs between each of the soil minerals was observed; however, with increasing ionic strength, the removal of MWCNTs from the aqueous phase followed the order smectite $>$ kaolinite $>$ shale (weakest-to-largest MWCNT association). As ionic strength increased, the MWCNT removal tendency for smectite and kaolinite was inversely correlated to the mineral surface potential. However, the electrostatic potential of shale is higher than either kaolinite or smectite, yet shale demonstrated the strongest sorption of MWCNTs (Zhang et al., 2012b). This was attributed to the large, hydrophobic, organic content of shale, which is able to strongly sorb MWCNTs. Hence, under these soil conditions, the transport of CNMs in soils is directly correlated with mineral hydrophobicity, but inversely correlated with surface potential (Zhang et al., 2012b). It is therefore imperative that studies of nanomaterial fate and behaviour in soils include detailed information regarding soil mineralogy.

\subsection{The impact of CNM preparation methods, functional groups and UV exposure}

In addition to the influence of soil type and properties, the properties of CNMs themselves vary greatly depending on an array of parameters. As commercial applications of CNMs will likely employ surface functional groups and a variety of different preparation techniques, nanoparticle properties and behaviour within the environment will become increasingly complex (Turco et al., 2011). For example, the physicochemical properties of pristine $n \mathrm{C}_{60}$, such as surface charge and particle size, heavily depend on the method of preparation, with a corresponding impact upon the stability of the nanomaterial (Chen and Elimelech, 2008, 2009; Isaacson et al., 2011). As discussed previously, deposition and aggregation of CNMs in their pristine state is highly susceptible to variations in soil water ionic strength; however, the exact extent of sensitivity is known to vary significantly according to the method of preparation. For example, in an aqueous solution, the deposition of $n \mathrm{C}_{60}$ occurs in $\mathrm{NaCl}$ at concentrations of $18 \mathrm{mM}$ when prepared by sonication $(100 \mathrm{~W}$ probe, $30 \mathrm{~min}$ ) (Qu et al., 2012) and 30 and $32 \mathrm{mM} \mathrm{NaCl}$ when prepared by solvent exchange methods (Chen and Elimelech, 2008; Smith et al., 2008). However, most investigations have been conducted in simple solutions of electrolytes using pristine $n \mathrm{C}_{60}$ and in complex environmental systems (Qu et al., 2012). As a result, the effects of cation valence on the stability of CNMs may substantially differ from those in a laboratory setting.

Typically, agglomeration of CNMs in the presence of divalent $\left(\mathrm{Ca}^{2+}\right)$ cations occurs to a greater extent than with monovalent $\left(\mathrm{Na}^{+}\right)$cations. However, when exposed to solar irradiation, $n \mathrm{C}_{60}$ can undergo surface oxidation and decomposition (Hou and Jafvert, 2008, 2009), with large implications for environmental behaviour and fate $(\mathrm{Qu}$ et al., 2012). Following exposure to UV-A (the largest component of UV radiation in sunlight), the oxygen-containing functional groups formed on $n \mathrm{C}_{60}$ hindered aggregation in $\mathrm{NaCl}$ solutions due to their elevated hydrophilicity and negative surface charge (Hou and Jafvert, 2009). Conversely, neutralisation of the negative surface charge on oxidised $n \mathrm{C}_{60}$ due to interactions with $\mathrm{Ca}^{2+}$ ions when suspended in $\mathrm{CaCl}_{2}$ can result in particle agglomeration ( $\mathrm{Li}$ and Liang, 2007). This potentially occurs due to the charge screening ability of $\mathrm{Ca}^{2+}$ relative to $\mathrm{Na}^{+}$, which reduces the stability of colloids (Li and Liang, 2007). Qu et al. (2012) expanded upon this work through studying the effects of UV-A exposure for either $20 \mathrm{~h}$ or $7 \mathrm{~d}$ on the rate of deposition and the attachment efficiency of $n \mathrm{C}_{60}$ onto silica bead surfaces. The stability of $n \mathrm{C}_{60}$ increased proportionally with increasing UV-A exposure time against aggregation in solutions containing $\mathrm{NaCl}$, which was attributed to the increase in surface oxidation and hydrophilicity (Qu et al., 2012). Furthermore, while the attachment efficiency of $n \mathrm{C}_{60}$ exposed to UV-A for $7 \mathrm{~d}$ was at a maximum in $\mathrm{NaCl}$ concentrations of $250 \mathrm{mM}$, attach- 
ment decreased following an increase in $\mathrm{NaCl}$ concentration to $300 \mathrm{mM}$. This indicates that stability of $n \mathrm{C}_{60}$-containing oxygen surface functional groups was attributed to the hydration force and not DLVO forces, which was more significant with the $7 \mathrm{~d}$ UV-exposed $n \mathrm{C}_{60}$ than either the pristine or the $20 \mathrm{~h} \mathrm{UV}$ due to the greater hydrophilicity (Qu et al., 2012).

In other investigations, surface immobilisation of macromolecules, such as HAs at environmentally relevant concentrations, has increased the solubility of $\mathrm{C}_{60}$ due to the effect of steric hindrance caused by the sorbed SOM and a reduction in the hydrophobicity of the nanoparticle surface, preventing reaggregation and reducing attachment efficiency $(\mathrm{Li}$ et al., 2009; Qu et al., 2012). However, Qu et al. (2012) found $7 \mathrm{~d}$ UV-exposed $n \mathrm{C}_{60}$ had negligible surface sorption of either HWM or LMW HAs due to the negative surface charge and elevated surface hydrophilicity. Hence, DOM is likely to be less significant in determining the suspension stability of irradiated $n \mathrm{C}_{60}$ (Qu et al., 2012). A similar relationship may occur due to the formation of oxygen-containing hydroxyland carboxyl-groups on MWCNTs due to surface oxidation, which can promote colloidal stability and hydrophilicity of CNTs in addition to inducing alterations to surface charge (Shieh et al., 2007; Smith et al., 2009). This is illustrated by $\mathrm{Hu}$ et al. (2005), in which carboxylic acid groups as a result of nitric acid treatment of SWCNTs had high $\zeta$ potentials $(-28 \mathrm{mV})$ over a $\mathrm{pH}$ range of $2-10$, indicating their moderate stability in water in contrast to pristine CNTs (Hu et al., 2005). Reduced deposition of pristine $n \mathrm{C}_{60}$ occurred on silica glass beads coated in HMW HA rather than LMW HA due to steric hindrance (Qu et al., 2012). The effect was more pronounced at lower ionic strengths due to electrostatic repulsion between charge groups resulting in a more stretchedout conformation of HA molecules (Qu et al., 2012). However, both HMW and LMW HA-coated beads facilitated the deposition of $7 \mathrm{~d}$ UV-exposed $n \mathrm{C}_{60}$, with reduced sensitivity to changes in ionic strength as a result of reduced steric hindrance (due to the compact conformation of HAs at high ionic strengths $(\sim 60 \mathrm{mM}))$, lower surface potential and increased hydrogen bonding between the oxygen-containing groups of the functionalised $n \mathrm{C}_{60}$ and nitrogen and oxygen groups on the HA (Qu et al., 2012).

Comparatively determining the relative importance of CNM functionalization and ionic strength on CNTs and $n \mathrm{C}_{60}$ behaviour in soils is difficult due to the myriad of different experimental configurations. To overcome this, Jaisi and Elimelech (2009) used carboxyl-functionalised SWCNTs and $n \mathrm{C}_{60}$ (radius of $51 \mathrm{~nm}$ ) in natural soil columns, containing $29 \%$ clay and pore sizes of $22 \mu \mathrm{m}$, to determine the impact of ionic strength on particle transport and deposition. As ionic strength increased $(0.03-100 \mathrm{mM})$, the rate of SWCNT deposition within the soil column also increased, with the observed effect more apparent with divalent cations $\left(\mathrm{Ca}^{2+}\right)$ than monovalent cations $\left(\mathrm{K}^{+}\right)$. Interestingly, while $n \mathrm{C}_{60}$ was highly sensitive to variations in ionic strength, far lower deposition rates were observed. It was proposed that the struc- ture and shape of SWCNTs, in particular their large aspect ratio and bulky agglomerated states, in addition to soil particle heterogeneity increased the straining effect and retention by the soil matrix (Jaisi and Elimelech, 2009). Nanomaterial structural conformation is therefore a further consideration in the relative extent to which CNMs will be dispersed and transported within the soil, with $n \mathrm{C}_{60}$ more likely to experience leaching than SWCNTs under a variety of solution chemistries (Jaisi and Elimelech, 2009) within negatively charged soil media.

Functionalization status is therefore a fundamental consideration to the behaviour of CNMs, resulting in distinct characteristics, which significantly modify behaviour in relation to their unfunctionalised counterparts. However, key questions as to the behaviour of CNMs within the environment remain unaddressed; for example, how does the repeated exposure of CNMs to weathering cycles within the soil influence their fate and behaviour?

\subsection{CNM-contaminant sorption, desorption and mobility in soils}

The ability of natural colloids to assist in the transport of organic contaminants has been well documented and reviewed (De Jonge et al., 2004; Sen and Khilar, 2006; Li et al., 2013). Typically, hydrophobic compounds such as PCBs and PAHs have limited environmental mobility due to strong sorption to SOM. Kan and Tomson (1990), however, demonstrated that high concentrations of colloidal materials such as DOM may enhance the transport of hydrophobic compounds such as phenanthrene and naphthalene by a factor of 1000 or greater, with possible implications for the spread of contamination and groundwater quality (De Jonge et al., 2004). Although CNMs may be tailored to suit specific requirements, their behaviour is not necessarily different to colloids naturally occurring in the environment (Colvin, 2003; Lead and Wilkinson, 2006). To determine the relevance of natural nanoparticle-facilitated transport of contaminants in porous media such as soils, Kretzschmar et al. (1999) identified four key factors that will be used as a framework for this section:

1. sufficiently high concentration of nanoparticles

2. mobility of the nanoparticles carrying sorbed HOCs

3. sorbate toxicity even when present in trace quantities

4. the ratio of sorption to desorption relative to the timescale of particle mobility.

The sorption affinity of CNMs for common environmental contaminants such as PAHs, known to pose significant risks to both the environment and human health due to their toxic properties (Menzie et al., 1992; Shaw and Connell, 1994; Cebulska-Wasilewska et al., 2007), has been reported as over 3 orders of magnitude greater than that of natural soil/sediments (Yang et al., 2006b). The potential for these 
emerging materials to become widespread in the soil environment, particularly those with a strongly hydrophobic nature and large reactive surface area such as CNMs, raises questions and concerns about the environmental consequences of their release (Pan and Xing, 2010).

\subsection{CNM contaminant sorption and desorption in soils}

Understanding the adsorption and desorption of HOCs to CNMs in soils is critical to the environmental risk assessment processes, as well as determining their potential applications as environmental adsorbents (Yang et al., 2006a). As the fundamentals of CNM-HOC sorption have been extensively reviewed, the reader is referred to a review by Ren et al. (2011) for a comprehensive overview. This section addresses the manner in which soils may alter the HOC sorption/desorption properties of CNMs, focusing specifically on two conflicting effects: (i) CNM dispersal by DOM (increasing the surface area and hence the number of adsorption sites; Hyung et al., 2006; Lin and Xing, 2008), versus (ii) the formation of CNM-DOM coatings (blocking and/or competing for adsorption sites reducing the number available for organic contaminants (Chen et al., 2008; Wang and Keller, 2009; Cui et al., 2011; Wang et al., 2011; Zhang et al., 2011)). The relative importance of these two phenomena is poorly understood in relation to their sorption and desorption of organic contaminants (Zhang et al., 2011; Pan and Xing, 2012), and it is highly dependent on both the nanoparticle properties, as well as the nature of SOM and the sorbate (Wang et al., 2009; Zhang et al., 2011; Lerman et al., 2013).

In assessing the impact of OM on CNM sorption in the environment, further complications arise as contaminants are able to sorb to both the CNM and CNM-OM coating (X. Wang et al., 2008). Hyung and Kim (2008) identified that SOM adsorption to nanotubes was highly variable depending on the type of SOM, occurring proportionally to its aromatic carbon content. This has implications for determining the ability of CNMs to sorb organic compounds, yet most investigations fail to consider the role of different OM fractions in CNT-pollutant interactions (Lerman et al., 2013).

X. Wang et al. (2008) assessed the extent to which HAs and peptone altered the sorption of phenanthrene, naphthalene or 1-naphthol onto MWCNTs (outer diameter of $40 \mathrm{~nm}$ ), by fitting sorption data with Freundlich and Polanyi models. Their results showed that each type of DOM resulted in nonlinear sorption isotherms to the MWCNTs, following the order peptone $>$ HAs. Although the inherent sorptive ability of $\mathrm{HA}$ for each of the contaminants was more limited than that of pristine MWCNTs, HA coatings did not result in large changes to the sorption of any of the contaminants, which is inconsistent with models indicating that "fouling" of sorption sites by DOM will reduce contaminant sorption capacity (Carter and Weber, 1994; X. Wang et al., 2008). The authors proposed that either uneven coating of the MWCNT by HA occurred, or that the anticipated sorption reduction as a re- sult of polar moieties from the HA coating was offset due to the increase in $\mathrm{O}$-containing moieties resulting in particle repulsion and dispersal, exposing new sites available for HOC sorption. Contrastingly, peptone, due to the large quantity sorbed relative to each of the other DOM fractions, resulted in the largest reduction in available sorption sites (X. Wang et al., 2008). Similar interactions as to the relative ability of different OM coatings to alter CNM sorption have been identified by Cui et al. (2011) and Gai et al. (2011). Although direct comparison of the studies is not possible due to the different particles used, Cui et al. (2011) found HAs, TAs and peptone pre-interacted with SWCNTs resulting in the formation of polar functional groups on the nanotube surface, reducing the area available for phenanthrene sorption in the order of peptone $>$ TAs $>$ HAs. Similarly, Gai et al. (2011) identified a reduction in $\mathrm{C}_{60}$ agglomerate sizes due to the dispersal effects of HA, increasing atrazine sorption due to dispersal and rearrangement, rather than interactions between the atrazine and HA (Gai et al., 2011). Hence, it may be argued that the impact of DOM on CNM-HOC sorption is dependent on the type of OM present and possibly also CNM type.

Within a soil environment, Li (2012) identified the sorption behaviour of naphthalene, phenanthrene and fluorine in a sandy loam soil, silt loam soil and Ottawa sand was unaffected following amendment of MWCNTs at concentrations of $2 \mathrm{mg} \mathrm{g}^{-1}$. For each contaminant investigated, sorption in both the MWCNT-amended and -unamended samples followed the same order, silt loam $>$ sandy loam $>$ sand, indicating the sorptive ability was driven by the organic carbon content (Li, 2012). Additionally, no difference between sorption isotherms of MWCNT-amended and -unamended samples was apparent, indicating that MWCNTs held no influence over the sample's inherent sorption capacity (Li, 2012). Similarly, the order in which PAHs sorbed was unaffected by the MWCNTs, occurring as anticipated according to the PAH's $K_{\text {ow }}$ values (Li, 2012). After 24 h of hydroxypropyl$\beta$-cyclodextrin (HPCD) desorption, no statistically significant differences in the percentage desorbed were detected between nanotube-amended and -unamended samples. Hence, the sorptive properties of MWCNTs in the environment may be similar to hard carbon, and did not influence the sorption/desorption behaviour of PAHs ( $\mathrm{Li}, 2012)$. When this is related to factor 4 proposed by Kretzschmar et al. (1999), in which the sorption to desorption ratio over a timescale of particle transport is considered, MWCNTs at $2 \mathrm{mg} \mathrm{kg}^{-1}$ concentration may not be considered significant in determining the behaviour of some PAHs in soils over the duration of their experiment. It may be, however, that factor 1 was not met, and the lack of MWCNT influence on PAH behaviour was merely a result of an insufficient quantity added to the soils, although a concentration of $2 \mathrm{mg} \mathrm{kg}^{-1}$ in environmentally relevant terms is likely to be unrealistically high. Hence, while this study indicates the sorption of multiple contaminants in the different soil types considered will not present an environmental concern in terms of pollutant mobilisation 
at $2 \mathrm{mg} \mathrm{kg}^{-1}$, it was not possible to consider the desorption of contaminants if transport were to occur.

An excellent study by Towell et al. (2011) assessed the extent to which HPCD extraction of HOCs with different physicochemical properties desorbed from soils amended with CNMs at concentrations between 0.05 and $0.5 \%$ (substantially larger than that employed by Li, 2012). At concentrations $\geq 0.05 \%$, Towell et al. (2011) identified significantly less ${ }^{14} \mathrm{C}-\mathrm{B}[a] \mathrm{P}$ extracted from $\mathrm{CNM}$-amended soils than ${ }^{14} \mathrm{C}$-phenanthrene due to the high hydrophobicity and a $\log K_{\text {ow }}$ value reducing the ability of ${ }^{14} \mathrm{C}-\mathrm{B}[a] \mathrm{P}$ to partition into the aqueous phase. This was exacerbated by the relatively $\mathrm{HMW}$ of ${ }^{14} \mathrm{C}-\mathrm{B}[a] \mathrm{P}$, which has been proven as a critical factor determining the bonding energy between SWCNTs and PAHs (Debnath et al., 2008; Towell et al., 2011). In relation to factor 4 , the nature of the sorbate may therefore influence the extent of desorption, and therefore the duration for which contaminants will remain sorbed. It may be proposed that CNM-sorbed HMW HOCs represent a greater risk of increased distance of transport within the environment than LMW HOCs.

While sorption of HOCs to CNMs in soils can occur, the extent of sorption and desorption is dependent on the type of $\mathrm{OM}$ and concentration of CNMs. With a view into the manner in which the properties outlined above potentially facilitate the transport of contaminants sorbed to CNMs in soils, studies in which mobility has been directly investigated will also be discussed.

\subsection{CNM-HOC mobility}

Once sorbed to freely suspended CNMs within the soil matrix, the mobility of HOCs is potentially increased; however, very few studies have focused on determining the impact of CNMs on contaminant movement in soils. An overview of the basic principal of CNM-facilitated HOC transport is presented in Fig. 1. Using column leach tests, Li (2012) examined the behaviour of phenanthrene, fluorine, naphthalene and pyrene in a saturated sandy loam soil amended with MWCNTs, functionalised MWCNTs (f-MWCNTs) and functionalised SWCNTs (f-SWCNTs) at a concentration of $5 \mathrm{mg} \mathrm{kg}^{-1}$. Significant retention of PAHs within the soil column was observed, due to the strong sorption of contaminants by CNTs and their limited mobility within the soil column (Li, 2012). In control soils and those amended with MWCNTs and f-MWCNTs, retention of PAHs occurred in the order naphthalene $<$ fluorine $<$ phenanthrene $<$ pyrene, with hydrophobic interactions between the CNTs and PAHs cited as the predominant cause of the observed pattern $(\mathrm{Li}$, 2012). Contrastingly, retention of contaminants within soils amended with f-SWCNTs occurred in the order of naphthalene $>$ fluorine $>$ phenanthrene $>$ pyrene, the sorption of which could not be accounted for by hydrophobic forces alone (Li, 2012). The trend was negatively correlated to molecular size, indicating that larger sorbate molecules may have less space for sorption due to the additional hydrophilic functional group (Yang et al., 2006b; Li, 2012). It was concluded that leaching behaviours were determined by physical characteristics of both CNTs and contaminants (Yang et al., 2006b; Li, 2012).

To determine the extent to which CNMs facilitated the movement of contaminants relative to various types of DOM, Zhang et al. (2011b) used saturated, sandy soil columns contaminated with either PCBs or phenanthrene to comparatively assess the mobilising ability of $n \mathrm{C}_{60}$ at $1.55-12.8 \mathrm{mg} \mathrm{L}^{-1}$ relative to DOM at $10-11 \mathrm{mg} \mathrm{L}^{-1}$. In this experiment, PCB $\left(12.4-13.9 \mu \mathrm{g} \mathrm{L}^{-1}\right)$ or phenanthrene $\left(14.8 \mu \mathrm{g} \mathrm{L}^{-1}\right)$ was added to a sonicated suspension of $n \mathrm{C}_{60}$ (1.55-12.8 $\mathrm{mg} \mathrm{L}^{-1}$ in electrolyte solution of $0.5 \mathrm{mM} \mathrm{NaCl}$ ), and tumbled end-over-end ( $3 \mathrm{rpm})$ for $7 \mathrm{~d}$ to reach adsorption equilibrium. The suspension was then added to the columns. The results showed that even the lowest concentration of $n \mathrm{C}_{60}$ significantly enhanced the dispersal of both PCB and phenanthrene, whereas columns containing only various types of DOM had no effect on contaminant transport (Zhang et al., 2011b). The enhanced contaminant mobilisation ability of $n \mathrm{C}_{60}$ relative to naturally occurring DOM was attributed to its unique porous structure and surface enthalpies of interaction, which generate a large sorption affinity together with an irreversibly or slowly desorbable fraction of adsorbed phenanthrene/PCBs (Hofmann and von der Kammer, 2009; Zhang et al., 2011b; Wang et al., 2012a). CNMs may therefore be much more efficient at enhancing the mobility of contaminants than natural colloidal materials.

Different processes of $n \mathrm{C}_{60}$ formation have also been identified as contributing to large differences in their ability to alter the fate and transport of contaminants (Wang et al., $2012 \mathrm{~b}$ ). Wang et al. (2012b) assessed $n \mathrm{C}_{60}$ samples prepared using either the standard solvent exchange method, eight different types of SOM or surfactant modifications, or by the phase transferring of $n \mathrm{C}_{60}$ from a solution of toluene to either SOM or a surfactant (Wang et al., 2012b). Their results indicated that while the mobility of $n \mathrm{C}_{60}$ was similar between each of the preparation methods, the contaminant mobilising capability significantly differed. Relative to the unmodified $n \mathrm{C}_{60}$, transport of PCBs through a saturated column of sandy soil increased by $42.2-227 \%$ with surfactant-modified $n \mathrm{C}_{60}$, and by $233-370 \%$ with SOM-modified samples (Wang et al., $2012 b)$. The results were attributed to both increased adsorption affinities and enhanced resistance to desorption due to alterations to $n \mathrm{C}_{60}$ aggregation properties as a result of the SOM surfactant (Wang et al., 2012b). During the process of aggregate formation, it is possible that a fraction of SOM or another surfactant was intercalated within the $\mathrm{C}_{60}$ aggregates, significantly influencing the porosity and geometry of the resulting $n \mathrm{C}_{60}$ aggregates, contributing to the enhanced desorption resistance of PCBs (Wang et al., 2012b). With differing types of SOM and surfactants, variations in the quantity and geometry of pores will occur, with the possibility that 


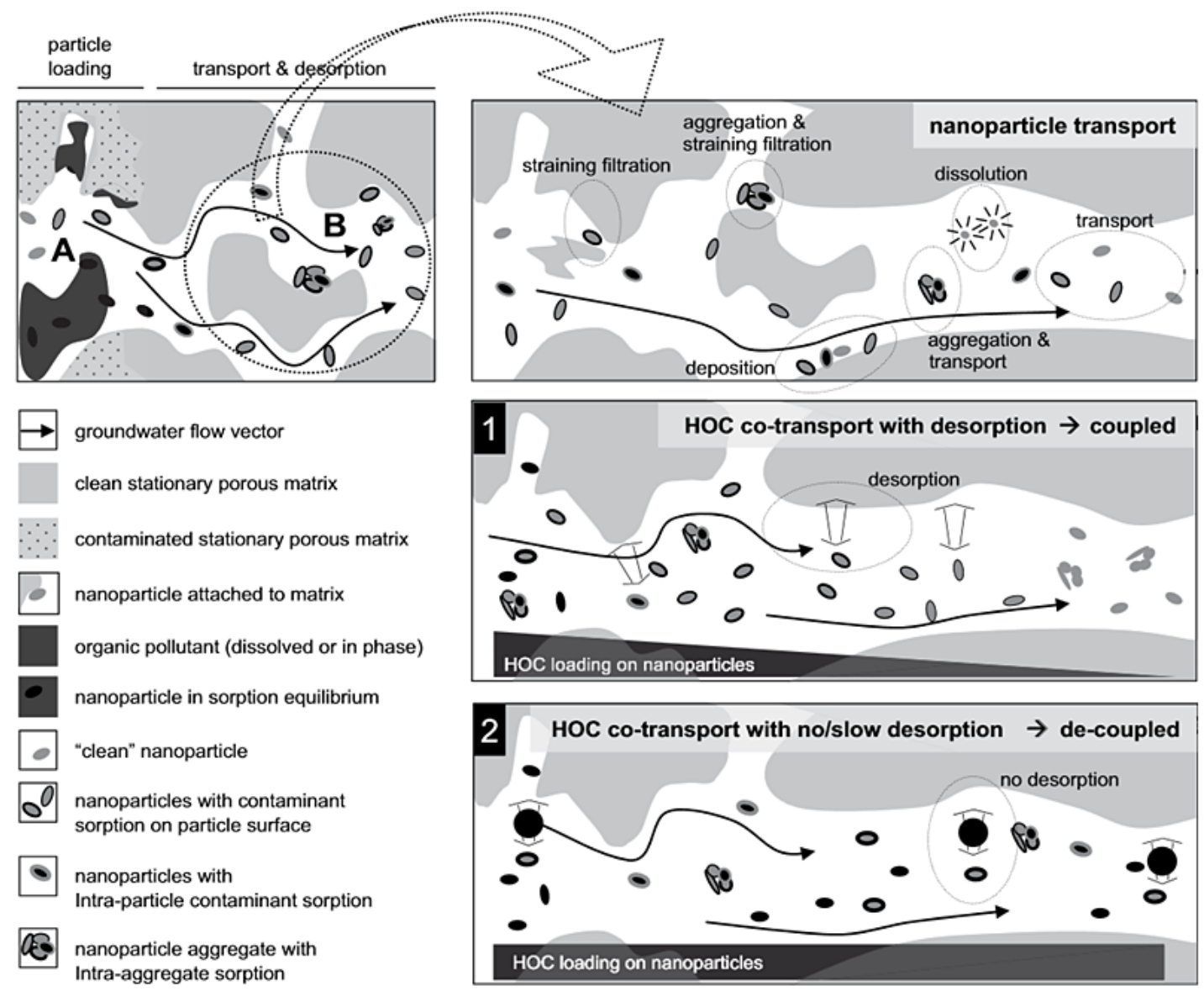

Figure 1. "Worst case scenario" processes by which CNMs may facilitate the transport of HOCs. Top-left panel: (A) HOC equilibrates with CNM and is (B) transported. The top-right panel shows the processes by which CNMs may be transported. The centre-right panel (1) shows the transport and rapid desorption of HOCs from CNMs. Equilibrium is achieved between the liquid phase, CNM and matrix. The bottom-right panel (2) shows slow desorption kinetics, with no desorption from the CNM (Hofmann and von der Kammer, 2009). Re-printed with permission from Elsevier ${ }^{\circledR} 2014$.

$n \mathrm{C}_{60}$ could be tailored to specific physicochemical properties for use in in situ site remediation (Wang et al., 2012b). Hence, the adsorption, desorption and transport of contaminants by $n \mathrm{C}_{60}$ will vary greatly depending on the condition of its formation (Wang et al., 2012a).

Using a different approach, Hofmann and von der Kammer (2009) computer modelled the extent to which CNMs could result in the movement of HOCs in soils under various scenario-based conditions, to determine when relevant CNM transport of sorbed HOCs might occur. Worst-case scenarios were adopted, assuming fully mobile CNMs within the porous medium, over a range of realistic yet high CNM concentrations $\left(100 \mathrm{mg} \mathrm{L}^{-1}-1 \mathrm{~g}^{-1}\right)$ occurring in aggregate sizes of $10-100 \mathrm{mM}$. It was also assumed that CNMs were preequilibrated with the $\mathrm{HOC}$ at source and that diffusion was the rate-limiting step for desorption (Hofmann and von der Kammer, 2009). From this, it was possible to estimate the fraction of contaminants bound to CNMs at different distances from the source over different time periods (days to years) using the Streamtube Model for Advective and Reactive Transport (SMART) (Finkel et al., 1998), combined with the application of retarded pore diffusion approximations (Bold et al., 2003) and combinations of two first-order rate expressions (Cornelissen et al., 1997). The results showed that for aggregates of $100 \mathrm{mM}, 2,7,40,75$, and $82 \%$ of bound contaminants were transported $>1 \mathrm{~m}$ at nanoparticle concentrations of $0.1,1,10,100$, and $1000 \mathrm{mg} \mathrm{L}^{-1}$, respectively. Conversely, modelled transportation of contaminants sorbed to aggregates of $10 \mathrm{mM}$ in size were reduced to $0.1,0.5,3.6$, and $8 \%$ for the same respective concentrations. Breakthrough of the $1 \mathrm{~m}$ modelled column did not occur in any of the considered scenarios and all contaminants remained bound to the nanoparticle.

Parameterisation of the ratio of desorption to sorption and particle transportation is achieved by the Damköhler number (Da) (Eq. 1) (Jennings and Kirkner, 1984), which was employed to simulate the HOC desorption from CNMs.

$D a_{\mathrm{NP}}=\lambda s$, 
where $D a_{\mathrm{NP}}$ is the Damköhler number for the NP, $\lambda$ the rate constants (first order) for the reaction $\left(\mathrm{s}^{-1}\right)$, and $s$ the average residence time within the system, which may also be expressed as average flow velocity (Hofmann and von der Kammer, 2009). A ratio of 0 identifies equilibrium between particle-contaminant interactions, whereas 1 indicates a decoupled transport (i.e. the HOC in the solution will be transported independently of contaminants sorbed to the $\mathrm{CNM}$ ) and $<0.01$ indicates fully decoupled transport. In these instances, HOCs sorbed to CNMs will not desorb over the transportation time frame, but rather relocate within the media (Hofmann and von der Kammer, 2009). At Da numbers $>100$, an equilibrium exists between the immobile porous media and mobile CNM (Kretzschmar et al., 1999; Bold et al., 2003), resulting in limited nanoparticle relocation of the contaminant (Hofmann and von der Kammer, 2009).

Hofmann and von der Kammer (2009) calculated Damköhler numbers for CNM aggregates of different sizes and partitioning coefficients according to the rate constant data shown in Fig. 2, and based on different flow velocities of $1 \mathrm{~m}$ in $50 \mathrm{~d}$ (fast flow) $1 \mathrm{~m}$ in 10 years (slow movement). It was inferred that the CNM-contaminant transport mechanisms are strongly dependent on the size of CNM agglomerates together with the distribution coefficients $\left(\log K_{\mathrm{d}}\right.$ ) (Hofmann and von der Kammer, 2009). For example, Fig. 2 shows contaminants sorbed to $1 \mathrm{mM}$ aggregates at a flow velocity of

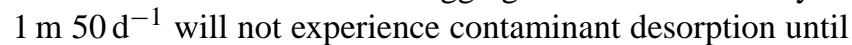
the $\log K_{\mathrm{d}}$ of HOC CNMs is $8 \mathrm{~m}^{3} \mathrm{~kg}^{-1}$, reaching equilibrium at $\log K_{\mathrm{d}} 1 \mathrm{~m}^{3} \mathrm{~kg}^{-1}$ (Hofmann and von der Kammer, 2009). However, at a flow velocity of $1 \mathrm{~m} \mathrm{yr}^{-1}$, decoupled transport will predominate for $1 \mathrm{mM}$ aggregates at a $\log K_{\mathrm{d}}$ of $9 \mathrm{~m}^{3} \mathrm{~kg}^{-1}$ reaching equilibrium at $\log K_{\mathrm{d}}$ of $2 \mathrm{~m}^{3} \mathrm{~kg}^{-1}$ (Hofmann and von der Kammer, 2009). It was concluded that under equilibrium sorption/desorption conditions, CNM mobility resulted in negligible transport of sorbed contaminants (Hofmann and von der Kammer, 2009). However, the mobility and concentration of CNMs becomes increasingly important in instances with slow to very slow desorption (Hofmann and von der Kammer, 2009). While there are many assumptions and simplifications associated with every modelling technique, the model identifies scenarios in which transport and desorption of sorbed contaminant could potentially occur, possibly providing useful guidelines for risk assessment if applied on a case-by-case basis. However, further work aimed specifically at validating the model against traditional column leach tests in both V-C and P-C soils and additional desorption kinetics are urgent prerequisites.

From the above discussion, it can be concluded that each of the four factors identified by Kretzschmar et al. (1999) for significant transport of contaminants by CNMs have been met. However, more work examining the subsurface transport of CNMs through well-defined soils of various types (such as clays, peats and silts) and CNMs with a variety of functional groups, sizes and sorbed compounds in both saturated and unsaturated conditions are required (Jaisi and
Elimelech, 2009; Petersen et al., 2011). Of studies that are available, variation in experimental conditions between the investigations renders comparisons of the efficiency of contaminant mobility between CNM types tentative until standardised comparative testing is conducted. Additionally, the molecular weights and sizes of CNMs may not be constant during their transport within the soil environment, due to their physical, chemical or biological interaction with soil components, which will likely influence their aggregation status, shape, surface charge (Pan and Xing, 2012), and possibly also their ability to sorb and mobilise contaminants over long timescales. Furthermore, definitive data of the desorption kinetics of HOCs from CNMs in soils are essential to understanding their ability to transport contaminants (Ibaraki and Sudicky, 1995; Choi and Yavuz Corapcioglu, 1997; Corapcioglu et al., 1999; Bold et al., 2003; Hofmann and von der Kammer, 2009), with slow desorption identified as a critical requirement (Roy and Dzombak, 1998). The lack of experimentally derived desorption kinetic data from a range of soil types and conditions makes determining the extent to which HOC sorption is strong enough and desorption slow enough to allow CNMs to transport sorbed HOCs, and the associated implications of transport, difficult to predict (Qu et al., 2012).

\section{CNM-microorganism interactions}

As soils represent one of the ultimate sinks for nanomaterials (Nowack and Bucheli, 2007), terrestrial microorganisms, which are a large component of soils, may be significantly affected (Navarro et al., 2008). The reader is directed to an excellent review by Holden et al. (2014), which evaluates the possible exposure concentrations of anthropogenic nanomaterials in a range of environmental compartments, and assesses their relevance. However, understanding the impact of CNMs on the soil microbial community is a subject still in its infancy (Dinesh et al., 2012). The extent to which CNMs interact with microflora will (in part) determine the extent of possible disruptions to bio-geochemical processes within soils that they may cause (Neal, 2008). This section discusses recent literature related to the modification of CNM fate and behaviour by microbiota, the toxicity of CNMs in soils and the possible implications for the biodegradation of contaminants.

\subsection{Biological modification of CNMs in soils}

The influence of microbial populations on the physical and chemical state of nanoparticles must be considered when discussing the ultimate fate of nanomaterials (Aruguete and Hochella, 2010). Degradation of $\mathrm{C}_{60}$ in aqueous solutions through photochemical processes have been identified by numerous investigations (Sect. 3.3) (Hou and Jafvert, 2008; Lee et al., 2009; Li et al., 2009), which may be an important step in both its breakdown and the activation of pre- 

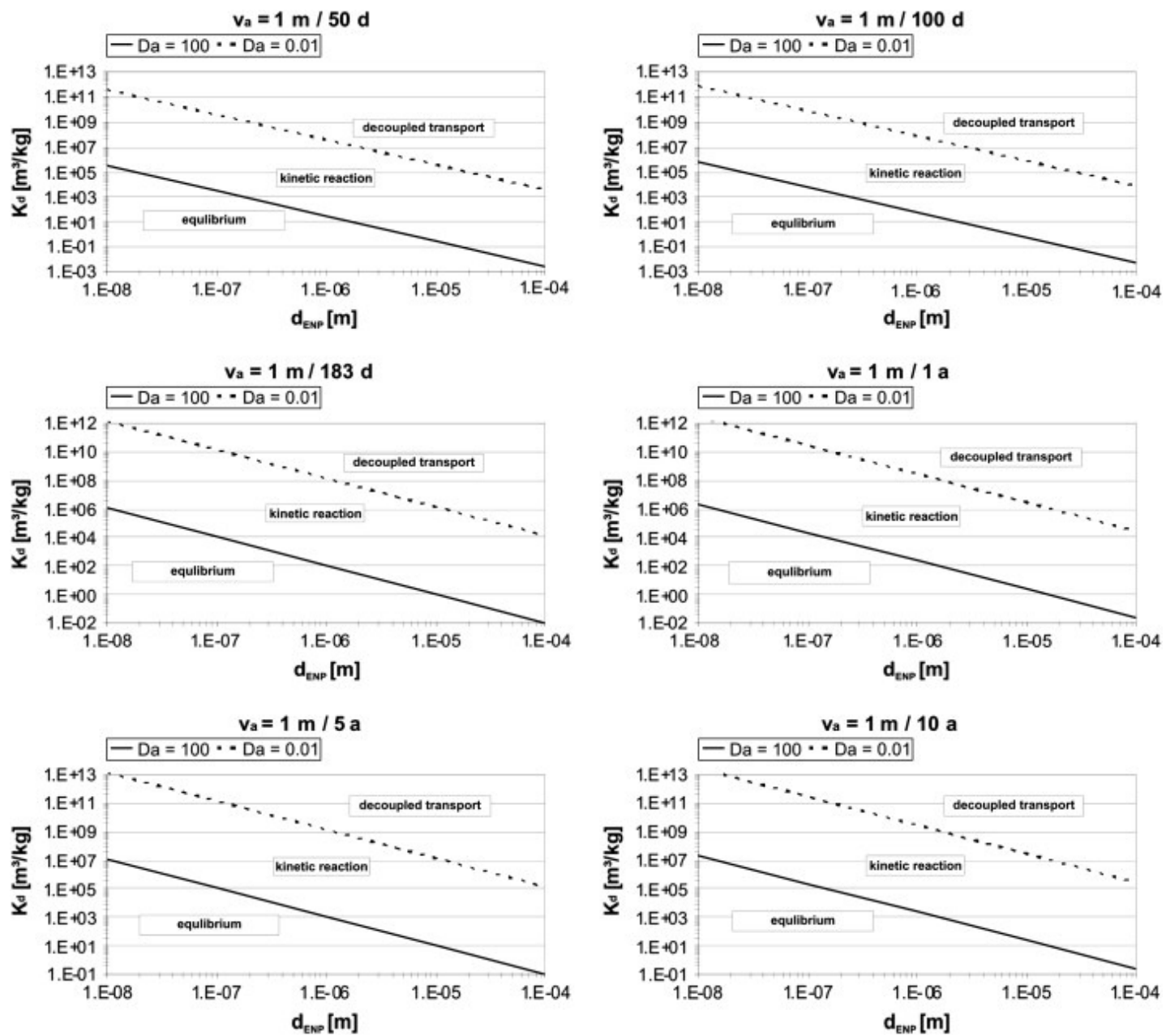

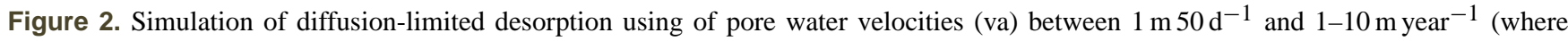
"a" = annum). The solid line represents the Damköhler number of 100 (representing equilibrium transport above which the HOC will equilibrate between the CNM and soil matrix), the dashed line indicates a Damköhler number of 0.01 (decoupled transport below which HOC desorption will not occur within the time frame of transport). If Damköhler numbers are $<100$ or $>0.01$, the kinetics of sorption should be considered in transport models (Hofmann and von der Kammer, 2009). Re-printed with permission from Elsevier ${ }^{\circledR} 2014$.

cursors for subsequent biological interactions (Turco et al., 2011). While $C_{60}$ photochemical reactions at the soil surface have not been studied, its oxidation and transformation to the more reactive fullerol (i.e. $\mathrm{C}_{60}-\mathrm{OH}$ ) has been observed in water and in the presence of oxygen (Turco et al., 2011). Following the abiotic photochemical modification of $\mathrm{C}_{60}$ through sunlight into fullerols, white-rot fungi was able to attack and subsequently incorporate a small amount of fullerol carbon into fungal biomass (lipids) after 32 weeks of decay (Schreiner et al., 2009). By contrast, unmodified $\mathrm{C}_{60}$ was recalcitrant to such attack (Schreiner et al., 2009); hence, following minor surface alterations, biological interactions with $\mathrm{C}_{60}$ were substantially altered, changing the fate of the particle. Similarly, the potential for horseradish peroxidase to biodegrade CNTs is strongly related to the presence of carboxyl groups on the nanotubes' surface, which permitted enzyme-mediated oxidation relative to pristine CNTs (Allen et al., 2008, 2009). Furthermore, Fenton's reagents oxidised carboxyl-functionalised SWCNTs (SWCNT-COOH) through the formation of hydroxyl radicals (Allen et al., 2008,2009 ). It has therefore been suggested that both white and brown rot mediated fungal activity could modify surface functionalised CNTs in a similar manner to fullerols (Turco et al., 2011).

Ultimately, Turco et al. (2011) suggested that the fate of $\mathrm{C}_{60}$ in soil is potentially controlled by the rate of abiotic alterations to the formation of more reactive precursors, as opposed to a simple dose response, and the toxicity of UVmodified CNMs in soils has not yet been investigated. If degradation of CNMs by fungi were to occur on a large scale in the natural environment, their potential environmental risk would be significantly reduced; however, it is unlikely to oc- 
cur in sufficiently large quantities to efficiently reduce any possible burden of CNM presence in soils.

\subsection{CNM toxicity to soil microorganisms}

The toxicity of CNMs is dependent upon the bioaccessibility of nanoparticles to bacteria, and retention of some the nanoparticles' reactivity (Neal, 2008). Currently, little literature is available related to the toxicity of CNMs within soils (Dinesh et al., 2012). Hence, the discussion presented here provides a theoretical estimation of the specific microbial communities that may be more vulnerable to soilborne CNMs, followed by an overview of recent CNM-amended soil toxicity findings published within the literature.

Soil conditions will ultimately dictate the extent to which CNMs are able to interact with terrestrial microflora. Based on the discussion earlier relating to the fate and behaviour of CNMs in soils, in addition to information regarding cell properties (Mehmannavaz et al., 2001), it may be possible to tentatively speculate as to the bioavailability or bioaccessibility of CNMs to different microbial populations. When assessing nanotoxicity, consideration must be given to both the likelihood of a nanoparticle coming into contact with microbial cells and the initial concentration added to soils in order to provide an accurate means of estimating the particle availability (Dinesh et al., 2012). A strong interplay exists between the dispersal status of nanoparticles and their bioaccessibility to specific soil microbial populations (Turco et al., 2011). As bacteria frequently adhere to surfaces in the soil environment, attached cells within biofilms constitute a large proportion of the bacterial community in the subsurface environment (Neal, 2008). Neal (2008) therefore proposed that the study of nanotoxicity towards biofilm communities is a more appropriate measure of toxicity in environmental systems than planktonic cells. However, it is conceivable that given appropriate DLVO and non-DLVO forces between CNMs, microorganisms and the soil matrix, CNMs could also become available to planktonic cells. One example of which may be that CNM-SOM coatings could result in easier access to the cell surface relative to uncoated particles due to the similarities in solubility between the cell membrane and surfactant; however, the coating itself may attenuate the toxicity due to a lack of physical contact between the CNM and a microbial cell (Lubick, 2008). Further work into the conditions under which CNMs will be available to different microbial communities in soils is needed.

The extent to which soils with different properties determine the toxicity of some CNMs was directly investigated by Chung et al. (2011). The impact of MWCNTs at 50, 500 and $5000 \mathrm{\mu g}^{-1}$ soil on the activity of soil microorganisms in a sandy loam (pH 6.98, OC content $17.69 \mathrm{~g} \mathrm{~kg}^{-1}$, CEC $13.51 \pm 0.78)$ and loamy sand $(\mathrm{pH} \mathrm{5.21,} \mathrm{OC} \mathrm{content}$ $8.33 \mathrm{~g} \mathrm{~kg}^{-1}$, CEC $9.05 \pm 0.10$ ) was considered. Based on an analysis of the activity of enzymes involved with cycling carbon (1,4- $\beta$-glucosidase, cellobiohydrolase, xylosidase), ni- trogen (1,4- $\beta$-acetylglucosaminidase) and phosphatase together with lower microbial biomass nitrogen and carbon in soil, their results indicated that MWCNTs exhibited antimicrobial properties within both soil types (Chung et al., 2011). As these findings are consistent with culture studies outside of the soil environment, in which reduced microbial activity was a result of membrane damage, physical piercing and oxidative stress (Kang et al., 2007; Simon-Deckers et al., 2009), the authors assumed that these antimicrobial mechanisms of action may be responsible, with their impact not attenuated by the different soil properties investigated.

Other investigations of nanotoxicity within soil using $n \mathrm{C}_{60}$ have found more limited toxicity effects. For example, Johansen et al. (2008) found microbial respiration and biomass to be unaffected by pristine $\mathrm{C}_{60}$ agglomerates $(50 \mathrm{~nm}-50 \mu \mathrm{m}$ size) applied at concentrations of $0,5,25$ and $50 \mathrm{mg} \mathrm{kg}^{-1}$ to dry, clay-loam-textured soil containing $2.5 \% \mathrm{OM}$ and with a $\mathrm{pH}$ of 6.7. However, polymerase chain reaction and denaturing gradient gel electrophoresis (PCR-DGGE) measurements of the diversity and number of bacteria over a $14 \mathrm{~d}$ period showed that a three- to fourfold reduction in rapidly growing bacteria occurred immediately following the addition of $\mathrm{C}_{60}$ (Johansen et al., 2008). The authors proposed the results may have been observed as a direct consequence of ROS formed by the $\mathrm{C}_{60}$, which disrupted DNA and lipids within membranes (Johansen et al., 2008). However, confirmation of ROS damage could not be acquired due to the complexity of the soil environment (Dinesh et al., 2012), and a recent publication by Chae et al. (2012) casts some doubt on the extent to which ROS are generated in the presence of SOM. It may therefore be considered more likely that the observed alterations to the diversity and number of bacteria may be an indirect result of a reduction in nutrient bioavailability due to adsorption by $\mathrm{C}_{60}$ (Johansen et al., 2008).

In a similar investigation, Tong et al. (2007) assessed the role aggregation status plays in determining nanotoxicity within soils. The impact of either $n \mathrm{C}_{60}$ at $1 \mu \mathrm{g} \mathrm{C}_{60} \mathrm{~g}^{-1}$ soil, or $1000 \mu \mathrm{C} \mathrm{C}_{60} \mathrm{~g}^{-1}$ soil in granular form on the function and structure of soil microbial community was assessed (Tong et al., 2007). The silty clay loam soil (pH of 6.9, OM content $4 \%$ ) was incubated with each of the nanoparticle treatments for $180 \mathrm{~d}$ (Tong et al., 2007). Both $\mathrm{C}_{60}$ and $n \mathrm{C}_{60}$ resulted in limited alteration to either the function or structure of microbial processes or communities (Tong et al., 2007). These findings are similar to those of Johansen et al. (2008), and consistent with other investigations in which the bioavailability and antibacterial activity of $n \mathrm{C}_{60}$ reportedly diminished following sorption to soil, with the overall sorption capacity dictated by the soil OM content (Li et al., 2008).

Despite differences in experimental setups between the studies by Johansen et al. (2008) and Tong et al. (2007), from the data presented, it is not possible to rule out the bioaccessibility and toxicity of $\mathrm{C}_{60}$ to a proportion of microbiota within soils. Although alterations to microbial respiration as a result of fullerene addition to soil were not observed in either 
study, functional substitution of specific impaired microorganisms may have occurred, masking any apparent variation (Ekelund et al., 2003; Johansen et al., 2008). The studies presented here provide credible insight into the possible toxicity of CNMs within the environment; however, insufficient data comparatively analysing the impact of all CNMs on microbial populations within a range of well-defined soil types is a major obstacle in determining their potential environmental impact. Experimental work aimed at addressing the realworld implications for particle toxicity to different microbial communities, systematically testing the factors determining the behaviour and fate of CNMs in soils highlighted previously, is required before firm conclusions can be drawn regarding the impact of CNMs on soil microbial activity and structure. Specifically, the implications of abiotic alterations and methods of CNM preparation on the bioaccessibility and toxicity to soil microbiota have received little investigation.

\subsection{The bioavailability and bioaccessibility of CNM-associated contaminants}

Sorption of contaminants is a fundamental mechanism in the regulation of organic compound bioavailability (Lou et al., 2011). Given their strong sorptive capability, the addition of CNMs to soil may result in the sequestration of organic contaminants, reducing their extractability and bioaccessibility, operating in a similar manner to hard or black carbon (Chen et al., 2007). However, the extent to which the processes identified in Sect. 4.1 impact upon the bioaccessibility of contaminants and biodegradation has not received much research within soils.

The conditions under which CNMs enter the soil are also critical to determining their impact upon contaminant bioaccessibility. Zhou et al. (2013) incubated ${ }^{14} \mathrm{C}-2,4-$ dichlorophenol $\left({ }^{14} \mathrm{C}-2,4-\mathrm{DCP}\right)$ in a soil (sandy loam, $\mathrm{pH}$ $6.31,2.5 \%$ OC, $46.7 \%$ clay. $37.9 \%$ silt, $15.4 \%$ sand) containing either $0,2,20$ or $2000 \mathrm{mg} \mathrm{kg}^{-1}$ SWCNTs or MWCNTs to determine the impact of carbon nanomaterials on the mineralisation, degradation and distribution of ${ }^{14} \mathrm{C}-2,4-\mathrm{DCP}$ in the soil. The impact of the order in which the nanomaterials were added to the soil was also assessed, with nanomaterials added either after spiking with ${ }^{14} \mathrm{C}-2,4-\mathrm{DCP}$, simulating disturbance of CNTs on pre-existing contamination in soils, or CNMs as a mixture with ${ }^{14} \mathrm{C}-2,4-\mathrm{DCP}$, simulating HOC degradation when carried or accumulated (concentrated) by CNMs within the environment from other sources. The CNMs were homogenised using ultrasonication at $90 \mathrm{w}$, $20 \mathrm{~Hz}$, for $5 \mathrm{~min}$ in deionized water, followed by shaking at $100 \mathrm{rpm}$ for $1 \mathrm{~d}$ prior to use. The results showed that CNTs added at concentrations $\leq 20 \mathrm{mg} \mathrm{kg}^{-1}$ to soil after spiking with ${ }^{14} \mathrm{C}-2,4-\mathrm{DCP}$ resulted in no significant effects on the time course of mineralisation, indicating that the activity of microorganisms was not significantly influenced, nor did the desorption from CNTs reduce ${ }^{14} \mathrm{C}-2,4-\mathrm{DCP}$ bioavailability in soil (Zhou et al., 2013). Following the addition of CNTs at $2000 \mathrm{mg} \mathrm{kg}^{-1}$ added after ${ }^{14} \mathrm{C}$-2,4-DCP spiking, mineralisation of ${ }^{14} \mathrm{C}-2,4-\mathrm{DCP}$ was significantly $(P<0.05)$ inhibited, which was attributed to a reduction in the aqueous phase concentration of ${ }^{14} \mathrm{C}-2,4-\mathrm{DCP}$ in soil solution by $1 / 5$ and $1 / 12$ for SWCNTs and MWCNTs, respectively (Zhou et al., 2013). However, significant inhibitory effects on the degradation of ${ }^{14} \mathrm{C}-2,4-\mathrm{DCP}$ when pre-sorbed to CNTs occurred at a CNT concentration of $20 \mathrm{mg} \mathrm{kg}^{-1}$.

These results show that CNT interactions with contaminants within the soil environment reduced the number of available sorption sites, with their sorptive ability further reduced by CNM aggregation and interaction with soil components such as humic substances, DOM, peptone and TA, which potentially coat CNTs modifying surface polarity, reducing surface area and hence reducing HOC sorption capacity as discussed in Sect. 4.1 (X. Wang et al., 2008; Cui et al., 2011; Zhou et al., 2013). As the adsorption of ${ }^{14} \mathrm{C}$ 2,4-DCP to CNTs was reversible, the bioaccessibility of 2,4DCP was not reduced; however, it may be possible that the indigenous microorganisms were not able to mineralise desorbed ${ }^{14} \mathrm{C}-2,4-\mathrm{DCP}$ at the same rate of desorption due to the possible toxicity effects of CNTs on microbial activity (Zhou et al., 2013). CNTs are therefore potentially able to increase the persistence of organic pollutants within soil by reducing biodegradation, with greater effects observed for pre-adsorbed contaminants (Zhou et al., 2013). However, it is possible to speculate about the environmental relevance of the investigation, as a concentration of $2000 \mathrm{mg} \mathrm{kg}^{-1}$ is likely several orders of magnitude higher than could realistically be assumed to exist (outside of localised "hotspots") within the environment (Zhou et al., 2013).

Similar results were obtained by Cui et al. (2011). Sediments $(20 \mathrm{~g})$ were first amended with either biochar $(100 \mathrm{mg})$, charcoal $(20 \mathrm{mg})$ or SWCNTs $(20 \mathrm{mg})$, then spiked with phenanthrene $\left(0.50 \mathrm{mg} \mathrm{kg}^{-1}\right)$. The mineralisation of phenanthrene by Mycobacterium vanbaalenii PYR1) was inhibited by $40.3 \pm 1.5,40.5 \pm 2.6$ and $29.5 \pm 3.5 \%$ for biochar, charcoal or SWCNTs, respectively. It was proposed that the larger surface area and pore volume of SWCNTs relative to the other sorbents was responsible for the reduced phenanthrene mineralisation. However, following the coating of SWCNTs with either HAs, TAs or peptone, a reduction in phenanthrene sorption occurred due to reduced pore volumes and surface area, ultimately also reducing the extent to which sorption to SWCNTs reduced mineralisation (Cui et al., 2011).

In addition to the impact of soil types on the impact of CNMs on organic contaminant sorption, properties of the organic chemicals within soils are also influential in dictating their interaction with different types of CNMs. Towell et al. (2011) assessed the impact of fullerene soot (FS), SWCNTs and MWCNTs at $0,0.05,0.1$ and $0.5 \%$ concentrations, on the HPCD extractability (proven as an indicator of PAH bioaccessibility to soil microflora (Reid et al., 2000; Doick et al., 2005; Stokes et al., 2005; Rhodes 
et al., 2008b) and mineralisation of ${ }^{14} \mathrm{C}$-phenanthrene, and HPCD extractability of ${ }^{14} \mathrm{C}$-benzo $[a]$ pyrene $\left({ }^{14} \mathrm{C}-\mathrm{B}[a] \mathrm{P}\right)$ in soils over an $80 \mathrm{~d}$ period. Soils were first amended with CNMs, and then spiked with the contaminant. At concentrations $\geq 0.05 \% \mathrm{CNMs},{ }^{14} \mathrm{C}$-phenanthrene mineralisation was significantly inhibited, suggesting enhanced PAH sorption reduced the aqueous substrate available for microbial mineralisation (Towell et al., 2011). Differences were also apparent between CNM types, with SWCNTs generally resulting in greater mineralisation inhibition in relation to MWCNTs and FS (Towell et al., 2011). However, at a concentration of $0.5 \% \mathrm{CNMs},{ }^{14} \mathrm{C}$-phenanthrene was mineralised to a greater extent with SWCNT amendments than FS. This disparity was attributed to variation in rates of phenanthrene desorption from the solid to aqueous phase, as desorption hysteresis occurs more commonly with fullerenes than CNTs due to differences in aggregate structure and availability of sorption sites (Cheng et al., 2005; Yang and Xing, 2007; Towell et al., 2011). The HPCD extractability of ${ }^{14} \mathrm{C}$-phenanthrene was significantly reduced as a result of CNM amendment in a concentration-dependant manner due to increased numbers of sorption sites resulting in enhanced phenanthrene sorption (Towell et al., 2011). However, while the HPCD extractability of ${ }^{14} \mathrm{C}-\mathrm{B}[a] \mathrm{P}$ decreased with increasing concentrations of SWCNTs and MWCNTs, no significant concentrationdependant differences were observed with FS (Towell et al., 2011). The ability of CNMs to sorb and hence modify the bioaccessibility of HOCs is therefore dependent on the differences in physicochemical properties of the PAH in relation to the properties of the CNM. However, the study did not consider possible differences in the toxicity of CNMs between particle types when discussing variations in mineralisation trends.

When considering the fraction of contaminants sorbed to CNMs within these investigations, and the resulting reduced bioavailability, two schools of thought may be adopted: (i) over time the nondegradable, bound fraction may innocuously degrade (Gevao et al., 2000a), or (ii) the bound fraction is potentially remobilised over long timescales with potential environmental implications (Gevao et al., 2000b). This draws on the discussion by Semple et al. (2013), in which the significance of distinguishing between bioavailability and bioaccessibility is significant, particularly when dealing with environmental "super sorbents" such as CNMs with reference to remediation of contaminated land and risk assessment. Semple et al. (2004) defined bioavailability as "that which is freely available to cross an organism's cellular membrane from the medium the organism inhabits at a given time", and is considered as a rate of substrate delivery to cells. While bioaccessibility encompasses this fraction, it additionally extends to those which are potentially available over time, but are currently chemically or physically removed from the microorganism (Semple et al., 2004). In other words, it provides a definition of the total extent of substrate that will be available to cells. Arguably, bioaccessibility is of rela- tively greater importance when considering the fate and behaviour of CNM-sorbed contaminants, due to the larger temporal range and lack of implied immediacy. However, under some environmental conditions, microbial colonisation of CNM agglomerates can occur, with potential implications for the bioaccessibility of the bound contaminant fraction.

\subsection{Microbial sorption and biofilm formation}

While the toxicity of CNMs in soil is dependent on their bioaccessibility in addition to retention of reactivity, if agglomerates of CNMs are present with a reduced cytotoxic nature, it is conceivable that interstitial gaps in the agglomerate with mesopore dimensions will result in their increased suitability for the sorption of microorganisms (Agnihotri et al., 2005; Upadhyayula and Gadhamshetty, 2010). When this is related to the previous discussion of CNM contaminant sorption and the implications for biodegradation, it is possible to reconsider the lack of bioaccessibility of CNM-sorbed contaminants reported in some studies, and consider their potential to increase contaminant bioaccessibility in certain situations. Properties of particular importance when considering CNMs for such applications include (i) structures with high porosities readily colonisable by microorganisms, (ii) potential ability to encourage biofilm formation through offering a buffering capacity, and (iii) the ability to adsorb high concentrations of contaminants from bulk solution yet regulate the microbial biodegradation through desorption (Abu-Salah et al., 1996).

Biofilms are groups of well-organised, adjoining cells encapsulated within a matrix of insoluble, extracellular polymetric substances (EPS) (Morikawa, 2006). EPS encapsulation supports cell substance and growth through the trapping, binding and dissemination of external nutrients by charged polysaccharide groups (Cheng et al., 2007), and offers greater protection against external stresses within the environment relative to those residing in a planktonic state (Pang et al., 2005). Materials that allow a high degree of bacterial colonisation and possibly biofilm formation are potentially suited to facilitating biodegradation (Upadhyayula and Gadhamshetty, 2010), which is typically most effective when microorganisms are in a biofilm state as opposed to planktonic, due to greater bioavailability, protection and adaptability to toxic conditions and hence more rapid pollutant degradation (Singh and Cameotra, 2004; Singh et al., 2006). Furthermore, bacterial colonisation may stabilise nanoparticle aggregates as polysaccharides, such as those generated by bacteria, have been observed to significantly increase the aggregation of $\mathrm{C}_{60}$ fullerene, reducing particle mobility within the environment (Espinasse et al., 2007).

Upadhyayula and Gadhamshetty (2010) conducted hypothetical calculations to determine the quantity of cells that an agglomerate of CNTs could potentially sorb. The dimensions of a typical bacterium such as Shewanella oneidensis are $2 \mu \mathrm{m}$ in height with a radius of $0.5 \mu \mathrm{m}$, resulting in a surface 
area of $7.85 \times 10^{-12} \mathrm{~m}^{2}$. Assuming that $10 \%$ of the surface area of $0.1 \mathrm{~g}$ of CNTs added to media was available for bacterial sorption, the CNTs would be able to sorb $3.18 \times 10^{13}$ S. oneidensis cells (Upadhyayula and Gadhamshetty, 2010). Furthermore, Upadhyayula et al. (2009) confirmed the adsorptive capacity of nanotubes for the bacterial strain Bacillus subtilis to be 37 times greater than the capacity of activated carbon; however, this may vary depending upon pore volumes and surface area, which are key determinants of immobilisation capacity (Upadhyayula and Gadhamshetty, 2010). Given these parameters, it is conceivable that biofilms could develop on CNM aggregates given sufficient pore volumes and diminished CNM reactivity.

When the potential for biofilm development on CNMs is considered in relation to their HOC sorptive ability and aggregation within soils, it has been suggested that CNMs may be useful for enhancing biodegradation of organic pollutants that cannot be easily concentrated. With CNM aggregates behaving as an organic chemical collector and accumulator, biofilm development on CNMs potentially increases the bioavailability/bioaccessibility of the contaminant (Yang et al., 2006b). Given adequate reversibility of organic compound adsorption and limited desorption hysteresis, sorption of bacterial cells to the surface of CNM aggregates may shorten the diffusion distance, facilitating the utilisation of the sorbed organic compound by the bacteria. This is well illustrated by Yan et al. (2004), who studied the removal efficiency of microcystin (MC) toxins from solution by Ralstonia solanacearum bacteria (Gram-negative cells which are able to readily coalesce on fibrous material) immobilised as a biofilm on a nontoxic form of CNTs. Their results showed that the removal efficiencies of MCs were $20 \%$ greater by CNT biological composites than either CNTs or bacteria alone (Yan et al., 2004). The findings were explained through absorption of large amounts of MCs and $R$. solanacearum by CNTs, resulting in a concerted biodegradation reaction (Yan et al., 2004). In a similar investigation, Kanepalli and Donna (2006) used CNT-bacteria nanocomposites to assess the bioremediation of highly persistent trichloroethylene (TCE) in groundwater. The study revealed that TCE instantly sorbed to bacteria nanocomposites, which was later released to bacteria that were immobilised on the surface and metabolised.

Xia et al. (2013) studied the bioavailability and desorption (Tenax TA) of ${ }^{14} \mathrm{C}$ phenanthrene aged over $60 \mathrm{~d}$ with four different MWCNTs with varying surface areas in aqueous solution. MWCNTs significantly $(P<0.05)$ reduced the mineralisation of phenanthrene in accordance with their properties, with particles possessing larger specific surface areas together with large meso- and micropore volumes resulting in the lowest mineralisation efficiencies. Bacteria were also observed to colonise the surface of MWCNT aggregates, proportional to the quantity of phenanthrene desorbed through Tenax TA extractions (Xia et al., 2013). Although slight changes to the physical appearance of the bacteria were ob- served when sorbed to MWCNT aggregates, potentially indicating a toxicity effect, the ability of the cells to metabolise phenanthrene sorbed to low surface area particles may not have been significantly reduced (Xia et al., 2013). However, the lack of a control sample in which the metabolism of cells under conditions devoid of CNMs was assessed limited the ability of the paper to determine the overall impact of MWCNT aggregates on phenanthrene mineralisation.

Very little information is available on how CNMs act within soil matrices, especially in relation to their adsorption to organic fractions, organic pollutants and their subsequent toxicity (Dinesh et al., 2012). With an angelus sorbents such as black carbon (BC), elevated mineralisation of a phenanthrene substrate has been observed as a direct result of $\mathrm{BC}$ addition to soil, which was tentatively attributed to microbial sorption and utilisation of phenanthrene from the sorbed phase (Rhodes et al., 2008a, 2012). Only one study has identified an increase in contaminant mineralisation in soils following the addition of CNMs. Xia et al. (2010) studied phenanthrene biodegradation and desorption characteristics (using XAD-2) in 21-40 d aged MWCNT-amended soils relative to soils amended with wood char and black carbon. Following each ageing interval, Agrobacterium (the degrading inoculum) was added to the soil, and the contaminant degradation efficiency was measured. After 28 and $40 \mathrm{~d}$ ageing, the degradation efficiency in MWCNT-amended soils was 54.2 and $24.6 \%$, respectively,; wood char amended 73.5 and $25.1 \%$, respectively, and black carbon amended 83.8 and $38.3 \%$, respectively. Thus, a reduction in bioavailability of contaminants sorbed to each of the sorbents with increasing soil contact time is observed (Xia et al., 2010), together with the relatively low bioavailability of contaminants sorbed to MWCNTs relative to other environmental sorbents. Desorption studies identified similar residual concentrations of phenanthrene; however, during rapid stages of degradation, desorption rates were found to underpredict the rate of degradation (Xia et al., 2010). This potentially suggests that for each of the sorbents, phenanthrene was available to bacteria either through the promotion of desorption or direct access (Xia et al., 2010).

Given the discussion above, it is possible to consider an additional factor to those proposed by Kretzschmar et al. (1999) in Sect. 4, to determine the significance of contaminant-facilitated transport by CNMs. If the CNMsorbed contaminant is available to the cells through utilisation from the sorbed phase, the importance of desorption of sorbed compounds from CNMs during transport is reduced. It is therefore proposed that incorporation of a fifth factor, "the bioavailability and bioaccessibility of CNM sorbed contaminants to microorganisms from the solid phase" may be appropriate, inferring that bioaccessibility through desorption investigations may lead to incorrect assumptions. However, substantially more work is required to identify the exact mechanism involved in these findings, and the specific conditions under which contaminant and microbial sorption 
to CNMs could potentially result in toxicity from the CNM itself, from the sorbed contaminant or both (Nowack and Bucheli, 2007). It is also possible that under some environmental conditions, rapid desorption or excessive bioavailability of sorbed contaminants may shock load sorbed bacteria and prove toxic (Upadhyayula and Gadhamshetty, 2010). Biodegradation of contaminants sorbed to CNMs therefore still requires substantial investigation into specific combinations of pollutants and microorganisms (Upadhyayula and Gadhamshetty, 2010), to determine whether the bioaccessibility of sorbed contaminants is either increased or decreased, and if the addition of CNMs will increase the mobility of contaminants in the environment. The general paucity of knowledge regarding the duration for which contaminants will remain sorbed to CNMs requires addressing to determine the long-term stability of contaminants sorbed to different nanoparticle types. Furthermore, the extent to which CNMs influence the transformation residues of HOCs in soils such as bound residues formed during organic pollution degradation in soil is unknown (Barriuso et al., 2008; Shan et al., 2011; Zhou et al., 2013).

\section{Summary and conclusions}

The complex and dynamic nature of both soil environments and CNM physicochemical properties generates enormous uncertainty in attempting to predict their behaviour and impact on contaminant sorption, sequestration and transport as well as microbial interactions. This review argues that the fate and behaviour of CNMs in soils is influenced by multiple parameters such as the type and quantity of SOM, the type of clay particles present, the dominant charge characteristics of the matrix as dictated by the soil inorganic fraction, and the properties of the CNM, each of which is heavily influenced by $\mathrm{pH}$ and ionic strength. In addition, to a small extent, biological activity has been shown to modify the carbon nanomaterial fate. However, presently no research has been conducted into the manner in which these factors interact and collaboratively influence the fate and behaviour of CNMs in real environmental scenarios; therefore additional research is required.

The extent to which CNMs are able to modify the behaviour of contaminants in soils and facilitate their transport is dependent on the CNM concentration, the properties of SOM, molecular weight of the HOC and the interaction of the CNM with the HOC before its addition to soils. When present in sufficient concentrations, CNMs have the ability to facilitate the transport of co-existing contaminants such as PAHs to a greater extent than naturally occurring colloids such as DOM, the extent of which is dependent on the physicochemical properties of the contaminant, CNM functionalization status, aggregation size and method of preparation. Further work derived from experimental research is needed to address the lack of data relating to the transport of CNMs through soils of different properties. Additionally, CNM-HOC desorption kinetics within soils require defining, as this presently limits our understanding of the significance of CNM-facilitated transport.

Finally, CNMs are undoubtedly efficient sorbents for a range of HOCs. However, while a reduction in the bioaccessibility of contaminants in soils following the addition of CNMs has been demonstrated (Towell et al., 2011), further research is required before their sorbtive abilities can be applied to the remediation of contaminated soils. Specifically, information regarding the stability of sorbed contaminants, as well as their potential to increase contaminant mobilisation together with other secondary effects, are as yet too poorly understood to fully anticipate the possible environmental impact of CNMs. To determine the behaviour of CNMs within soils, it is concluded that no one set of environmental or CNM characteristics can be viewed in isolation. Hence, given the diverse array of variables, it is argued that risk assessment of CNMs within the soil environment should be conducted on a case-by-case basis. A detailed analysis of other environmental compartments in which CNMs can potentially accumulate, such as sediments, should also be considered.

Edited by: R. Zornoza

\section{References}

Abu-Salah, K., Shelef, G., Levanon, D., Armon, R., and Dosoretz, C. G.: Microbial degradation of aromatic and polyaromatic toxic compounds adsorbed on powdered activated carbon, J. Biotechnol., 51, 265-272, 1996.

Agnihotri, S., Mota, J. P. B., Rostam-Abadi, M., and Rood, M. J.: Structural characterization of single-walled carbon nanotube bundles by experiment and molecular simulation, Langmuir, 21, 896-904, 2005.

Allen, B. L., Kichambare, P. D., Gou, P., Vlasova, I. I., Kapralov, A. A., Konduru, N., Kagan, V. E., and Star, A.: Biodegradation of Single-Walled Carbon Nanotubes through Enzymatic Catalysis, Nano Letters, 8, 3899-3903, 2008.

Allen, B. L., Kotchey, G. P., Chen, Y., Yanamala, N. V. K., KleinSeetharaman, J., Kagan, V. E., and Star, A.: Mechanistic Investigations of Horseradish Peroxidase-Catalyzed Degradation of Single-Walled Carbon Nanotubes, J. Am. Chem. Soc., 131, 17194-17205, 2009.

Almecija, D., Blond, D., Sader, J. E., Coleman, J. N., and Boland, J. J.: Mechanical properties of individual electrospun polymernanotube composite nanofibers, Carbon, 47, 2253-2258, 2009.

Aruguete, D. M. and Hochella, M. F.: Bacteria-nanoparticle interactions and their environmental implications, Environ, Chem., 7, 3-9, 2010.

Barriuso, E., Benoit, P., and Dubus, I. G.: Formation of pesticide nonextractable (bound) residues in soil: Magnitude, controlling factors and reversibility, Environ. Sci. Technol, 42, 1845-1854, 2008.

Bold, S., Kraft, S., Grathwohl, P., and Liedl, R.: Sorption/desorption kinetics of contaminants on mobile particles: Modeling and experimental evidence, Water Resour. Res., 39, 1329, doi:10.1029/2002WR001798, 2003. 
Campbell, E. E. B. and Rohmund, F.: Fullerene reactions. Rep. Prog. Phys., 63, 1061, doi:10.1088/0034-4885/63/7/202, 2000.

Carter, M. C. and Weber, W. J.: Modeling Adsorption of TCE by Activated Carbon Preloaded by Background Organic Matter, Environ. Sci. Technol., 28, 614-623, 1994.

Cebulska-Wasilewska, A., Pawłyk, I., Panek, A., Wiecheć, A., Kalina, I., Popov, T., Georgieva, T. and Farmer, P. B.: Exposure to environmental polycyclic aromatic hydrocarbons: Influences on cellular susceptibility to DNA damage (sampling Košice and Sofia), Mutation Res., 620, 145-154, 2007.

Chae, S.-R., Xiao, Y., Lin, S., Noeiaghaei, T., Kim, J.-O., and Wiesner, M. R.: Effects of humic acid and electrolytes on photocatalytic reactivity and transport of carbon nanoparticle aggregates in water, Water Res., 46, 4053-4062, 2012.

Chappell, M. A., George, A. J., Dontsova, K. M., Porter, B. E., Price, C. L., Zhou, P., Morikawa, E., Kennedy, A. J., and Steevens, J. A.: Surfactive stabilization of multi-walled carbon nanotube dispersions with dissolved humic substances, Environ. Pollut., 157, 1081-1087, 2009.

Chen, J., Chen, W., and Zhu, D.: Adsorption of Nonionic Aromatic Compounds to Single-Walled Carbon Nanotubes: Effects of Aqueous Solution Chemistry, Environ. Sci. Technol., 42, 7225-7230, 2008.

Chen, K. L. and Elimelech, M.: Interaction of Fullerene (C60) Nanoparticles with Humic Acid and Alginate Coated Silica Surfaces: Measurements, Mechanisms, and Environmental Implications, Environ. Sci. Technol., 42, 7607-7614, 2008.

Chen, K. L. and Elimelech, M.: Relating Colloidal Stability of Fullerene (C60) Nanoparticles to Nanoparticle Charge and Electrokinetic Properties, Environ. Sci. Technol., 43, 7270-7276, 2009.

Chen, W., Duan, L., and Zhu, D.: Adsorption of Polar and Nonpolar Organic Chemicals to Carbon Nanotubes, Environ. Sci. Technol., 41, 8295-8300, 2007.

Chen, Z., Yadghar, A. M., Zhao, L., and Mi, Z.: A review of environmental effects and management of nanomaterials, Toxicol. Environ. Chem., 93, 1227-1250, 2011.

Cheng, G., Zhang, Z., Chen, S., Bryers, J. D., and Jiang, S.: Inhibition of bacterial adhesion and biofilm formation on zwitterionic surfaces, Biomaterials, 28, 4192-4199, 2007.

Cheng, X., Kan, A. T., and Tomson, M. B.: Uptake and Sequestration of Naphthalene and 1,2-Dichlorobenzene by C60, J. Nanoparticle Res., 7, 555-567, 2005.

Chibowski, E., Espinosa-Jiménez, M., Ontiveros-Ortega, A., and Giménez-Martin, E.: Surface Free Energy, Adsorption and Zeta Potential in Leacril/Tannic Acid System, Langmuir, 14, 52375244, 1998.

Chijiwa, T., Arai, T., Sugai, T., Shinohara, H., Kumazawa, M., Takano, M., Kawakami, S., and Kawakami, S.: Fullerenes found in the Permo-Triassic mass extinction period, Geophys. Res. Lett., 26, 767-770, 1999.

Choi, H. and Yavuz Corapcioglu, M.: Transport of a non-volatile contaminant in unsaturated porous media in the presence of colloids, J. Contaminant Hydrol., 25, 299-324, 1997.

Chung, H., Son, Y., Yoon, T. K., Kim, S., and Kim, W.: The effect of multi-walled carbon nanotubes on soil microbial activity, Ecotoxicol. Environ. Safety, 74, 569-575, 2011.

Colvin, V. L.: The potential environmental impact of engineered nanomaterials, Nature Biotechnol., 21, 1166-1170, 2003.
Corapcioglu, M. Y., Jiang, S., and Kim, S.-H.: Comparison of Kinetic and Hybrid-Equilibrium Models Simulating ColloidFacilitated Contaminant Transport in Porous Media, Transport in Porous Media, 36, 373-390, 1999.

Cornelissen, G., Van Noort, P. C. M., and Govers, H. A. J.: Desorption kinetics of chlorobenzenes, polycyclic aromatic hydrocarbons, and polychlorinated biphenyls: Sediment extraction with Tenax ${ }^{\circledR}$ and effects of contact time and solute hydrophobicity, Environ. Toxicol. Chem., 16, 1351-1357, 1997.

Cui, X. Y., Jia, F., Chen, Y. X. and Gan, J.: Influence of singlewalled carbon nanotubes on microbial availability of phenanthrene in sediment, Ecotoxicology, 20, 1277-1285, 2011.

Darlington, T. K., Neigh, A. M., Spencer, M. T., Guyen, O. T. N., and Oldenburg, S. J.: Nanoparticle characteristics affecting environmental fate and transport through soil, Environ. Toxicol. Chem., 28, 1191-1199, 2009.

Debnath, S., Cheng, Q., Hedderman, T. G., and Byrne, H. J.: An experimental study of the interaction between single walled carbon nanotubes and polycyclic aromatic hydrocarbons, Physica Stat. Sol. (B), 245, 1961-1963, 2008.

De Jonge, L. W., Kjaergaard, C., and Moldrup, P.: Colloids and Colloid-Facilitated Transport of Contaminants in Soils: An Introduction, Vadose Zone J., 3, 321-325, 2004.

Dinesh, R., Anandaraj, M., Srinivasan, V., and Hamza, S.: Engineered nanoparticles in the soil and their potential implications to microbial activity, Geoderma, 173-174, 19-27, 2012.

Doick, K. J., Dew, N. M., and Semple, K. T.: Linking Catabolism to Cyclodextrin Extractability:? Determination of the Microbial Availability of PAHs in Soil, Environ. Sci. Technol., 39, 88588864, 2005.

Doudrick, K., Herckes, P., and Westerhoff, P.: Detection of Carbon Nanotubes in Environmental Matrices Using Programmed Thermal Analysis, Environ. Sci. Technol., 46, 12246-12253, 2012.

Ekelund, F., Olsson, S., and Johansen, A.: Changes in the succession and diversity of protozoan and microbial populations in soil spiked with a range of copper concentrations, Soil Biol. Biochem., 35, 1507-1516, 2003.

Espinasse, B., Hotze, E. M., and Wiesner, M. R.: Transport and Retention of Colloidal Aggregates of C60 in Porous Media: Effects of Organic Macromolecules, Ionic Composition, and Preparation Method, Environ. Sci. Technol., 41, 7396-7402, 2007.

Esquivel, E. V. and Murr, L. E.: A TEM analysis of nanoparticulates in a Polar ice core, Materials Characterization, 52, 15-25, 2004.

Finkel, M., Liedl, R., and Teutsch, G.: Modelling surfactantenhanced remediation of polycyclic aromatic hydrocarbons, Environ. Model. Softw., 14, 203-211, 1998.

Gai, K., Shi, B., Yan, X., and Wang, D.: Effect of Dispersion on Adsorption of Atrazine by Aqueous Suspensions of Fullerenes, Environ. Sci. Technol., 45, 5959-5965, 2011.

Gevao, B., Mordaunt, C., Semple, K. T., Piearce, T. G., and Jones, K. C.: Bioavailability of Nonextractable (Bound) Pesticide Residues to Earthworms, Environ. Sci. Technol., 35, 501507, 2000a.

Gevao, B., Semple, K. T., and Jones, K. C.: Bound pesticide residues in soils: a review, Environ. Pollut., 108, 3-14, $2000 \mathrm{~b}$.

Giles, J.: Top five in physics, Nature, 441, p. 265, 2006.

Gottschalk, F., Sonderer, T., Scholz, R. W., and Nowack, B.: Modeled Environmental Concentrations of Engineered Nanomateri- 
als (TiO2, ZnO, Ag, CNT, Fullerenes) for Different Regions, Environ. Sci. Technol., 43, 9216-9222, 2009.

Gottschalk, F., Sonderer, T., Scholz, R. W., and Nowack, B.: Possibilities and limitations of modeling environmental exposure to engineered nanomaterials by probabilistic material flow analysis, Environ. Toxicol. Chem., 29, 1036-1048, 2010.

Han, Z., Zhang, F., Lin, D., and Xing, B.: Clay Minerals Affect the Stability of Surfactant- Facilitated Carbon Nanotube Suspensions, Environ. Sci. Technol., 42, 6869-6875, 2008.

Heymann, D., Chibante, L. P., Brooks, R. R., Wolbach, W. S., and Smalley, R. E.: Fullerenes in the Cretaceous-Tertiary BoundaryLayer, Science, 265, 645-647, 1994.

Hofmann, T. and Von Der Kammer, F.: Estimating the relevance of engineered carbonaceous nanoparticle facilitated transport of hydrophobic organic contaminants in porous media, Environ. Pollut., 157, 1117-1126, 2009.

Holden, P. A., Klaessig, F., Turco, R. F., Priester, J. H., Rico, C. M., Avila-Arias, H., Mortimer, M., Pacpaco, K., and GardeaTorresdey, J. L.: Evaluation of Exposure Concentrations Used in Assessing Manufactured Nanomaterial Environmental Hazards: Are They Relevant?, Environ. Sci. Technol., 48, 10541-10551, doi:10.1021/es502440s, 2014.

Hou, W.-C. and Jafvert, C. T.: Photochemical Transformation of Aqueous C60 Clusters in Sunlight, Environ. Sci. Technol., 43, 362-367, 2008.

Hou, W.-C. and Jafvert, C. T.: Photochemistry of Aqueous C60 Clusters: Evidence of $1 \mathrm{O} 2$ Formation and its Role in Mediating C60 Phototransformation, Environ. Sci. Technol., 43, 52575262, 2009.

Hu, H., Yu, A., Kim, E., Zhao, B., Itkis, M. E., Bekyarova, E., and Haddon, R. C.: Influence of the Zeta Potential on the Dispersability and Purification of Single-Walled Carbon Nanotubes, J. Phys. Chem. B, 109, 11520-11524, 2005.

Hyung, H. and Kim, J.-H.: Natural Organic Matter (NOM) Adsorption to Multi-Walled Carbon Nanotubes: Effect of NOM Characteristics and Water Quality Parameters, Environ. Sci. Technol., 42, 4416-4421, 2008.

Hyung, H., Fortner, J. D., Hughes, J. B., and Kim, J.-H.: Natural Organic Matter Stabilizes Carbon Nanotubes in the Aqueous Phase, Environ. Sci. Technol., 41, 179-184, 2006.

Ibaraki, M. and Sudicky, E. A.: Colloid-facilitated contaminant transport in discretely fractured porous media: 1 . Numerical formulation and sensitivity analysis, Water Resour. Res., 31, 29452960, 1995.

Isaacson, C., Zhang, W., Powell, T., Ma, X., and Bouchard, D.: Temporal Changes in Aqu/C60 Physical-Chemical, Deposition, and Transport Characteristics in Aqueous Systems, Environ. Sci. Technol., 45, 5170-5177, 2011.

Jafar, G. and Hamzeh, G.: Ecotoxicity of Nanomaterials in Soil, Ann. Biol. Res., 4, 86-92, 2013.

Jaisi, D. P. and Elimelech, M.: Single-Walled Carbon Nanotubes Exhibit Limited Transport in Soil Columns, Environ. Sci. Technol., 43, 9161-9166, 2009.

Jennings, A. A. and Kirkner, D. J.: Instantaneous Equilibrium Approximation Analysis, J. Hydraul. Eng., 110, 1700-1717, 1984.

Johansen, A., Pedersen, A. L., Jensen, K. A., Karlson, U., Hansen, B. M., Scott-Fordsmand, J. J., and Winding, A.: Effects of C60 fullerene nanoparticles on soil bacteria and protozoans, Environ. Toxicol. Chem., 27, 1895-1903, 2008.
Kan, A. T. and Tomson, M. B.: Ground water transport of hydrophobic organic compounds in the presence of dissolved organic matter, Environ. Toxicol. Chem., 9, 253-263, 1990.

Kanepalli, S. and Donna, F. E.: Enhancing the remediation of trichloroethene (TCE) using double-walled carbon nanotubes (DWCNT), United States Geological Survey, 2006.

Kang, S., Pinault, M., Pfefferle, L. D., and Elimelech, M.: SingleWalled Carbon Nanotubes Exhibit Strong Antimicrobial Activity, Langmuir, 23, 8670-8673, 2007.

Köhler, A. R., Som, C., Helland, A., and Gottschalk, F.: Studying the potential release of carbon nanotubes throughout the application life cycle, J. Cleaner Product., 16, 927-937, 2008.

Kretzschmar, R., Borkovec, M., Grolimund, D., and Elimelech, M.: Mobile Subsurface Colloids and Their Role in Contaminant Transport, in: Advances in Agronomy, edited by: Donald, L. S., Academic Press, 1999.

Kuznar, Z. A. and Elimelech, M.: Adhesion Kinetics of Viable Cryptosporidium parvum Oocysts to Quartz Surfaces, Environ. Sci. Technol., 38, 6839-6845, 2004.

Kwon, J.-H.: Destabilization of aqueous colloidal C60 nanoparticles in the presence of various organic matter, CLEAN - Soil, Air, Water, 40, 472-478, 2012.

Lead, J. R. and Wilkinson, K. J.: Aquatic colloids and nanoparticles: Current knowledge and future trends, Environ. Chem., 3, 159171, 2006.

Lee, J., Cho, M., Fortner, J. D., Hughes, J. B., and Kim, J.-H.: Transformation of Aggregated C60 in the Aqueous Phase by UV Irradiation, Environ. Sci. Technol., 43, 4878-4883, 2009.

Lee, M. C., Snoeyink, V. L., and Crittenden, J. C.: Activated carbon adsorption of humic substances, American Water Works Association, 73, 440-446, 1981.

Lerman, I., Chen, Y., and Chefetz, B.: Adsorption of Contaminants of Emerging Concern by Carbon Nanotubes: Influence of Dissolved Organic Matter, in: Functions of Natural Organic Matter in Changing Environment, edited by: Xu, J., Wu, J. and He, Y., Springer Netherlands, 2013.

Li, D., Lyon, D. Y., Li, Q., and Alvarez, P. J. J.: Effect of soil sorption and aquatic natural organic matter on the antibacterial activity of a fullerene water suspension, Environ. Toxicol. Chem., 27, 1888-1894, 2008.

Li, Q., Xie, B., Hwang, Y. S., and Xu, Y.: Kinetics of C60 Fullerene Dispersion in Water Enhanced by Natural Organic Matter and Sunlight, Environ. Sci. Technol., 43, 3574-3579, 2009.

Li, S.: A study of environmental fate and application of commercially available carbon nanotubes, Doctor of Philosophy Thesis, Texas Tech University, 2012.

Li, W., Zhu, X., He, Y., Xing, B., Xu, J., and Brookes, P. C.: Enhancement of water solubility and mobility of phenanthrene by natural soil nanoparticles, Environ. Pollut., 176, 228-233, 2013.

Li, W. J. and Liang, W. J.: Loss of characteristic absorption bands of 600 conjugation systems in the addition with aliphatic amines, Spectrochimica Acta Part A: Molecular and Biomolecular Spectroscopy, 67, 1346-1350, 2007.

Lin, D. and Xing, B.: Tannic Acid Adsorption and Its Role for Stabilizing Carbon Nanotube Suspensions, Environ. Sci. Technol., 42, 5917-5923, 2008.

Liu, C., Fan, Y. Y., Liu, M., Cong, H. T., Cheng, H. M., and Dresselhaus, M. S.: Hydrogen Storage in Single-Walled Carbon Nanotubes at Room Temperature, Science, 286, 1127-1129, 1999. 
Lou, L., Luo, L., Wang, W., Xu, X., Hou, J., Xun, B., and Chen, Y.: Impact of black carbon originated from fly ash and soot on the toxicity of pentachlorophenol in sediment, J. Hazardous Materials, 190, 474-479, 2011.

Lubick, N.: Risks of Nanotechnology Remain Uncertain, Environ. Sci. Technol., 42, 1821-1824, 2008.

Lucafò, M., Pacor, S., Fabbro, C., Da Ros, T., Zorzet, S., Prato, M., and Sava, G.: Study of a potential drug delivery system based on carbon nanoparticles: effects of fullerene derivatives in MCF7 mammary carcinoma cells, J. Nanoparticle Res., 14, 1-13, 2012.

Mauter, M. S. and Elimelech, M.: Environmental Applications of Carbon-Based Nanomaterials, Environ. Sci. Technol., 42, 58435859, 2008.

Mehmannavaz, R., Prasher, S. O., and Ahmad, D.: Cell surface properties of rhizobial strains isolated from soils contaminated with hydrocarbons: hydrophobicity and adhesion to sandy soil, Process Biochem., 36, 683-688, 2001.

Menzie, C. A., Potocki, B. B., and Santodonato, J.: Exposure to carcinogenic PAHs in the environment, Environ. Sci. Technol., 26, 1278-1284, 1992.

Mohanty, B., Anita, K. V., Claesson, P., and Bohidar, H. B.: Physical and anti-microbial characteristics of carbon nanoparticles prepared from lamp soot, Nanotechnology, 18, 445102, doi:10.1088/0957-4484/18/44/445102, 2007.

Morikawa, M.: Beneficial biofilm formation by industrial bacteria Bacillus subtilis and related species, J. Biosci. Bioeng., 101, 18, 2006.

Mueller, N. C. and Nowack, B.: Exposure Modeling of Engineered Nanoparticles in the Environment, Environ. Sci. Technol., 42, 4447-4453, 2008.

Navarro, E., Baun, A., Behra, R., Hartmann, N., Filser, J., Miao, A.J., Quigg, A., Santschi, P., and Sigg, L.: Environmental behavior and ecotoxicity of engineered nanoparticles to algae, plants, and fungi, Ecotoxicology, 17, 372-386, 2008.

Neal, A. L.: What can be inferred from bacterium-nanoparticle interactions about the potential consequences of environmental exposure to nanoparticles?, Ecotoxicology, 17, 362-371, 2008.

Nowack, B. and Bucheli, T. D.: Occurrence, behavior and effects of nanoparticles in the environment, Environ. Pollut., 150, 5-22, 2007.

Pan, B. and Xing, B.: Adsorption Mechanisms of Organic Chemicals on Carbon Nanotubes, Environ. Sci. Technol., 42, 90059013, 2008

Pan, B. and Xing, B.: Manufactured nanoparticles and their sorption of organic chemicals, Adv. Agronomy, 108, 137-181, 2010.

Pan, B. and Xing, B.: Applications and implications of manufactured nanoparticles in soils: a review, Euro. J. Soil Sci., 63, 437456, 2012.

Pang, C. M., Hong, P., Guo, H., and Liu, W.-T.: Biofilm formation characteristics of bacterial isolates retrieved from a reverse osmosis membrane, Environ. Sci. Technol., 39, 7541-7550, 2005.

Peretz, S. and Regev, O.: Carbon nanotubes as nanocarriers in medicine, Current Opinion Coll. Int. Sci., 17, 360-368, 2012.

Petersen, E. J. and Henry, T. B.: Methodological considerations for testing the ecotoxicity of carbon nanotubes and fullerenes: Review, Environ. Toxicol. Chem., 31, 60-72, 2012.

Petersen, E. J., Zhang, L., Mattison, N. T., O'carroll, D. M., Whelton, A. J., Uddin, N., Nguyen, T., Huang, Q., Henry, T. B., Holbrook, R. D., and Chen, K. L.: Potential Release Pathways, En- vironmental Fate, And Ecological Risks of Carbon Nanotubes, Environ. Sci. Technol., 45, 9837-9856, 2011.

Plata, D. L., Reddy, C. M., and Gschwend, P. M.: Thermogravimetry-Mass Spectrometry for Carbon Nanotube Detection in Complex Mixtures, Environ. Sci. Technol., 46, 12254-12261, 2012.

Qu, X., Alvarez, P. J. J., and Li, Q.: Impact of Sunlight and Humic Acid on the Deposition Kinetics of Aqueous Fullerene Nanoparticles (nC60), Environ. Sci. Technol., 46, 13455-13462, 2012.

Reid, B. J., Stokes, J. D., Jones, K. C., and Semple, K. T.: Nonexhaustive Cyclodextrin-Based Extraction Technique for the Evaluation of PAH Bioavailability, Environ. Sci. Technol., 34, 3174 3179, 2000.

Ren, X., Chen, C., Nagatsu, M., and Wang, X.: Carbon nanotubes as adsorbents in environmental pollution management: A review, Chem. Eng. J., 170, 395-410, 2011.

Rhodes, A. H., Carlin, A., and Semple, K. T.: Impact of Black Carbon in the Extraction and Mineralization of Phenanthrene in Soil, Environ. Sci. Technol., 42, 740-745, 2008a.

Rhodes, A. H., Dew, N. M., and Semple, K. T.: Relationship between cyclodextrin extraction and biodegradation of phenanthrene in soil, Environ. Toxicol. Chem., 27, 1488-1495, $2008 \mathrm{~b}$.

Rhodes, A. H., Riding, M. J., Mcallister, L. E., Lee, K., and Semple, K. T.: Influence of Activated Charcoal on Desorption Kinetics and Biodegradation of Phenanthrene in Soil, Environ. Sci. Technol., 46, 12445-12451, 2012.

Richards, J. J., Rice, A. H., Nelson, R. D., Kim, F. S., Jenekhe, S. A., Luscombe, C. K., and Pozzo, D. C.: Modification of PCBM Crystallization Via Incorporation of C60 in Polymer/Fullerene Solar Cells, Adv. Funct. Materials, 23, 514-522, 2012.

Riding, M. J., Martin, F. L., Trevisan, J., Llabjani, V., Patel, Ii, Jones, K. C., and Semple, K. T.: Concentration-dependent effects of carbon nanoparticles in gram-negative bacteria determined by infrared spectroscopy with multivariate analysis, Environ. Pollut., 163, 226-234, 2012a.

Riding, M. J., Trevisan, J., Hirschmugl, C. J., Jones, K. C., Semple, K. T., and Martin, F. L.: Mechanistic insights into nanotoxicity determined by synchrotron radiation-based Fourier-transform infrared imaging and multivariate analysis, Environ. Int., 50, 5665, 2012b.

Roy, S. B. and Dzombak, D. A.: Sorption nonequilibrium effects on colloid-enhanced transport of hydrophobic organic compounds in porous media, J. Contaminant Hydrol., 30, 179-200, 1998.

Sanchez, P. A.: Properties and management of soils in the tropics, New York, USA, John Wiley and Sons, 1976.

Sayes, C. M., Fortner, J. D., Guo, W., Lyon, D., Boyd, A. M., Ausman, K. D., Tao, Y. J., Sitharaman, B., Wilson, L. J., Hughes, J. B., West, J. L., and Colvin, V. L.: The Differential Cytotoxicity of Water-Soluble Fullerenes, Nano Letters, 4, 1881-1887, 2004.

Schierz, A., Parks, A. N., Washburn, K. M., Chandler, G. T., and Ferguson, P. L.: Characterization and Quantitative Analysis of Single-Walled Carbon Nanotubes in the Aquatic Environment Using Near-Infrared Fluorescence Spectroscopy, Environ. Sci. Technol., 46, 12262-12271, 2012.

Schreiner, K. M., Filley, T. R., Blanchette, R. A., Bowen, B. B., Bolskar, R. D., Hockaday, W. C., Masiello, C. A., and Raebiger, J. W.: White-Rot Basidiomycete-Mediated Decomposition of C60 Fullerol, Environ. Sci. Technol., 43, 3162-3168, 2009. 
Semple, K. T., Doick, K. J., Jones, K. C., Burauel, P., Craven, A., and Harms, H.: Peer Reviewed: Defining Bioavailability and Bioaccessibility of Contaminated Soil and Sediment is Complicated, Environ. Sci. Technol., 38, 228A-231A, 2004.

Semple, K. T., Riding, M. J., Mcallister, L. E., Sopena-Vazquez, F., and Bending, G. D.: Impact of black carbon on the bioaccessibility of organic contaminants in soil, J. Hazardous Materials, 261, 808-816, 2013.

Sen, T. K. and Khilar, K. C.: Review on subsurface colloids and colloid-associated contaminant transport in saturated porous media, Adv. Colloid Interface Sci., 119, 71-96, 2006.

Shan, J., Jiang, B., Yu, B., Li, C., Sun, Y., Guo, H., Wu, J., Klumpp, E., Schäffer, A., and Ji, R.: Isomer-Specific Degradation of Branched and Linear 4-Nonylphenol Isomers in an Oxic Soil, Environ. Sci. Technol., 45, 8283-8289, 2011.

Sharma, P. and Ahuja, P.: Recent advances in carbon nanotubebased electronics, Materials Res. Bull., 43, 2517-2526, 2008.

Shaw, G. and Connell, D.: Prediction and Monitoring of the Carcinogenicity of Polycyclic Aromatic Compounds (PACs), in: Reviews of Environmental Contamination and Toxicology, edited by: Ware, G., Springer New York, 1994.

Shieh, Y.-T., Liu, G.-L., Wu, H.-H., and Lee, C.-C.: Effects of polarity and $\mathrm{pH}$ on the solubility of acid-treated carbon nanotubes in different media, Carbon, 45, 1880-1890, 2007.

Simon-Deckers, A. L., Loo, S., Mayne-L'hermite, M., HerlinBoime, N., Menguy, N., Reynaud, C. C., Gouget, B., and Carriee, M.: Size-, Composition- and Shape-Dependent Toxicological Impact of Metal Oxide Nanoparticles and Carbon Nanotubes toward Bacteria, Environ. Sci. Technol., 43, 8423-8429, 2009.

Singh, P. and Cameotra, S. S.: Enhancement of metal bioremediation by use of microbial surfactants, Biochem. Biophys. Res. Comm., 319, 291-297, 2004.

Singh, R., Paul, D., and Jain, R. K.: Biofilms: implications in bioremediation, Trends in Microbiol., 14, 389-397, 2006.

Smith, B., Wepasnick, K., Schrote, K. E., Bertele, A. R., Ball, W. P., O'melia, C., and Fairbrother, D. H.: Colloidal Properties of Aqueous Suspensions of Acid-Treated, Multi-Walled Carbon Nanotubes, Environ. Sci. Technol., 43, 819-825, 2008.

Smith, B., Wepasnick, K., Schrote, K. E., Cho, H.-H., Ball, W. P., and Fairbrother, D. H.: Influence of Surface Oxides on the Colloidal Stability of Multi-Walled Carbon Nanotubes: A StructureProperty Relationship, Langmuir, 25, 9767-9776, 2009.

Snow, E. S., Perkins, F. K., Houser, E. J., Badescu, S. C., and Reinecke, T. L.: Chemical Detection with a Single-Walled Carbon Nanotube Capacitor, Science, 307, 1942-1945, 2005.

Sobek, A. and Bucheli, T. D.: Testing the resistance of single- and multi-walled carbon nanotubes to chemothermal oxidation used to isolate soots from environmental samples, Environ. Pollut., 157, 1065-1071, 2009.

Sollins, P., Robertson, G. P., and Uehara, G.: Nutrient mobility in variable- and permanent-charge soils, Biogeochemistry, 6, 181199, 1988.

Stokes, J. D., Paton, G. I., and Semple, K. T.: Behaviour and assessment of bioavailability of organic contaminants in soil: relevance for risk assessment and remediation, Soil Use Manage., 21, 475486, 2005.

Terashima, M. and Nagao, S.: Solubilization of [60]Fullerene in water by aquatic humic substances, Chem. Lett., 36, 302-303, 2007.
Tong, Z., Bischoff, M., Nies, L., Applegate, B., and Turco, R. F.: Impact of Fullerene (C60) on a Soil Microbial Community, Enviro. Sci. Technol., 41, 2985-2991, 2007.

Towell, M. G., Browne, L. A., Paton, G. I., and Semple, K. T.: Impact of carbon nanomaterials on the behaviour of 14Cphenanthrene and 14C-benzo-[a] pyrene in soil, Environ. Pollut., 159, 706-715, 2011.

Turco, R. F., Bischoff, M., Tong, Z. H., and Nies, L.: Environmental implications of nanomaterials: are we studying the right thing?, Current Opinion in Biotechnol., 22, 527-532, 2011.

Upadhyayula, V. K. K. and Gadhamshetty, V.: Appreciating the role of carbon nanotube composites in preventing biofouling and promoting biofilms on material surfaces in environmental engineering: A review, Biotechnol. Adv., 28, 802-816, 2010.

Upadhyayula, V. K. K., Deng, S., Smith, G. B., and Mitchell, M. C.: Adsorption of Bacillus subtilis on single-walled carbon nanotube aggregates, activated carbon and NanoCeram, Water Res., 43, 148-156, 2009.

Velasco-Santos, C., Martinez-Hernandez, A. L., Consultchi, A., Rodriguez, R., and Castaño, V. M.: Naturally produced carbon nanotubes, Chemical Phys. Lett., 373, 272-276, 2003.

Wang, L., Fortner, J. D., Hou, L., Zhang, C., Kan, A. T., Tomson, M. B., and Chen, W.: Contaminant-mobilizing capability of fullerene nanoparticles (nC60): Effect of solvent-exchange process in nC60 formation, Environ. Toxicol. Chem., 32, 329-336, 2012a.

Wang, L., Huang, Y., Kan, A. T., Tomson, M. B. and Chen, W.: Enhanced Transport of 2,2',5,5'-Polychlorinated Biphenyl by Natural Organic Matter (NOM) and Surfactant-Modified Fullerene Nanoparticles (nC60), Environ. Sci. Technol., 46, 5422-5429, 2012b.

Wang, P. and Keller, A. A.: Natural and Engineered Nano and Colloidal Transport: Role of Zeta Potential in Prediction of Particle Deposition, Langmuir, 25, 6856-6862, 2009.

Wang, P., Shi, Q., Liang, H., Steuerman, D. W., Stucky, G. D., and Keller, A. A.: Enhanced Environmental Mobility of Carbon Nanotubes in the Presence of Humic Acid and Their Removal from Aqueous Solution, Small, 4, 2166-2170, 2008.

Wang, X., Lu, J., and Xing, B.: Sorption of Organic Contaminants by Carbon Nanotubes: Influence of Adsorbed Organic Matter, Environ. Sci. Technol., 42, 3207-3212, 2008.

Wang, X., Tao, S., and Xing, B.: Sorption and Competition of Aromatic Compounds and Humic Acid on Multiwalled Carbon Nanotubes, Environ. Sci. Technol., 43, 6214-6219, 2009.

Wang, X., Shu, L., Wang, Y., Xu, B., Bai, Y., Tao, S., and Xing, B.: Sorption of Peat Humic Acids to Multi-Walled Carbon Nanotubes, Environ. Sci. Technol., 45, 9276-9283, 2011.

Xia, X., Li, Y., Zhou, Z., and Feng, C.: Bioavailability of adsorbed phenanthrene by black carbon and multi-walled carbon nanotubes to Agrobacterium, Chemosphere, 78, 1329-1336, 2010.

Xia, X., Zhou, C., Huang, J., Wang, R., and Xia, N.: Mineralization of phenanthrene sorbed on multiwalled carbon nanotubes, Environ. Toxicol. Chem., 32, 894-901, doi:10.1002/etc.2125, 2013.

Yan, H., Pan, G., Zou, H., Li, X., and Chen, H.: Effective removal of microcystins using carbon nanotubes embedded with bacteria, Chinese Sci. Bull., 49, 1694-1698, 2004.

Yang, K. and Xing, B.: Desorption of polycyclic aromatic hydrocarbons from carbon nanomaterials in water, Environ. Pollut., 145, 529-537, 2007. 
Yang, K., Wang, X., Zhu, L., and Xing, B.: Competitive Sorption of Pyrene, Phenanthrene, and Naphthalene on Multiwalled Carbon Nanotubes, Environ. Sci. Technol., 40, 5804-5810, 2006 a.

Yang, K., Zhu, L., and Xing, B.: Adsorption of Polycyclic Aromatic Hydrocarbons by Carbon Nanomaterials, Environ. Sci. Technol., 40, 1855-1861, 2006b.

Zhang, L., Petersen, E. J., and Huang, Q.: Phase Distribution of 14C-Labeled Multiwalled Carbon Nanotubes in Aqueous Systems Containing Model Solids: Peat, Environ. Sci. Technol., 45, 1356-1362, 2011a.

Zhang, L., Wang, L., Zhang, P., Kan, A. T., Chen, W., and Tomson, M. B.: Facilitated Transport of 2,2',5,5'-Polychlorinated Biphenyl and Phenanthrene by Fullerene Nanoparticles through Sandy Soil Columns, Environ. Sci. Technol., 45, 1341-1348, $2011 b$.
Zhang, L., Hou, L., Wang, L., Kan, A. T., Chen, W., and Tomson, M. B.: Transport of Fullerene Nanoparticles (nC60) in Saturated Sand and Sandy Soil: Controlling Factors and Modeling, Environ. Sci. Technol., 46, 7230-7238, 2012a.

Zhang, L., Petersen, E. J., Zhang, W., Chen, Y., Cabrera, M., and Huang, Q.: Interactions of 14C-labeled multi-walled carbon nanotubes with soil minerals in water, Environ. Pollut., 166, 75-81, 2012b.

Zhang, S., Shao, T., and Karanfil, T.: The effects of dissolved natural organic matter on the adsorption of synthetic organic chemicals by activated carbons and carbon nanotubes, Water Res., 45, 1378-1386, 2011.

Zhou, W., Shan, J., Jiang, B., Wang, L., Feng, J., Guo, H., and Ji, R.: Inhibitory effects of carbon nanotubes on the degradation of $14 \mathrm{C}$ 2,4-dichlorophenol in soil, Chemosphere, 90, 527-534, 2013. 